\title{
NATIONAL ADVISORY COMMITTEE FOR AERONAUTICS
}

\author{
REPORT 1148
}

\section{A SPECIAL INVESTIGATION TO DEVELOP A GENERAL METHOD FOR THREE-DIMENSIONAL PHOTOELASTIC STRESS ANALYSIS}

By M. M. FROCHT and R. G.UERNSEY, JR.

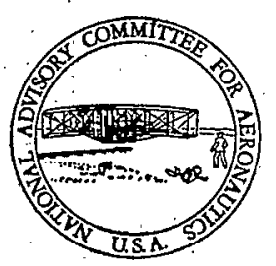




\section{REPORT 1148}

\section{A SPECIAL INVESTIGATION TO DEVELOP A GENERAL METHOD FOR THREE-DIMENSIONAL PHOTOELASTIC STRESS ANALYSIS}

By M. M. FROCHT and R. GUERNSEY, JR.

Illinois Institute of Technology 


\title{
National Advisory Committee for Aeronautics
}

\author{
Headquarters, 1724 F Street NW., Washington 25, D. C.
}

Created by act of Congress approved March 3, 1915, for the supervision and direction of the scientific study of the problems of flight (U. S. Cude, title 50, sec. 151). Its membership was increased from 12 to 15 by act approved March 2, 1929, and to 17 by act approved May 25, 1948. The members are appointed by the President, and serve as such without compensation.

Jerome C. Hunsaker, Sc. D., Massachusetts Institute of Technology, Chairman

Detlev W. Bronk, Ph. D., President, Rockefeller Institute for Medical Research, Vice Chairman

Hon. Joseph P. Adams, member, Civil Aeronautics Board. Allign V. Astin, Ph. D., Director, National Bureau of Standards. Leonard Carmichaed, Pir. D., Secretary, Smithsonian Institution.

Laurence C. Craigie, Lieutenant General, United States Air Force, Deputy Chief of Staff (Development).

James H. Doolittle, Sc. D., Vice President, Shell Oil Co.

Lloyd Harrison, Rear Admiral, United States Navy, Deputy and Assistant Chief of the Bureau of Aeronautics.

R. M. H Hzen, B. S., Director of Engineering, Allison Division, General Motors Corp.

William Littifewood, M. E., Vice President-Engineering, American Airlines, Inc.
Hon. Robert B. Murray, Jr., Under Secretary of Commerce for Transportation.

Ratph A. Ofstie, Vice Admiral, United States Navy, Deputy Chief of Naval Operations (Air).

Donald L. Putr, Lieutenant General, United States Air Force, Commander, Air Research and Development Command.

Arth UR E. Raymond, Sc. D., Vice President-Engineering, Douglas Aircraft Co., Inc.

Francis W. Reichelderter, Sc. D., Chief, United States Weather Bureau.

Theodore P. Wright, Sc. D., Vice President for Research, Cornell University.
Hugh L. Dryden, Ph. D., Director

John W. Crowley, JR., B. S., Associate Director for Research
John F. Victort, LL. D., Executive Secretary

E. H. Chamberlin, Executive Officer

Henry J. E. Reid, D. Eng., Director, Langley Aeronautical Laboratory, Langley Field, Va.

Smith J. DeFrance, D. Eng., Director, Ames Aeronautical Laboratory, Moffett Field, Calif.

Edward R. Sharp, Sc. D., Director, Lewis Flight Propulsion Laboratory, Cleveland Airport, Cleveland, Ohio

Langley Aeronattical Laboratory, Langley Field, Va.
Ames Aeronautical Laboratort, Moffett Field, Calif.
Lewis Flight Propulsion laboratory, Cleveland Airport, Cleveland, Ohio

Conduct, under unified control, for all agencies, of scientific research on the fundamental problems of flight 


\section{REPORT 1148}

\section{A SPECIAL INVESTIGATION TO DEVELOP A GENERAL METHOD FOR THREE-DIMENSIONAL PHOTOELASTIC STRESS ANALYSIS ${ }^{1}$}

By M. M. Frocht and R. Guernsey, JR.

\section{SUMMARY}

The method of strain measurement after annealing is reviewed and found to be unsatisfactory for the materials available in this country. A new, general method is described for the photoelastic determination of the principal stresses at any point of a general body subjected to arbitrary loads. The method has been applied to a sphere subjected to diametral compressive loads. The results show possibilities of high accuracy.

\section{INTRODUCTION}

It is known that purely photoelastic procedures cannot solve the general three-dimensional stress problem. The photoelastic method furnishes five independent equations, whereas the complete specification of the state of stress at a point requires six relations to determine six unknown stress components.

In order to obtain a sixth relation it has been suggested that the frozen slices removed from the model be annealed and strain measurements be made after annealing. This suggestion has recently received a rather extensive treatment from Prigorovsky and Preiss in Russia (reference 1). A careful analysis of this suggested method shows that its successful application requires model materials having relatively low values of Poisson's ratio at the elevated temperatures used in the freezing process. Such materials are not available in this country. Fosterite and Bakelite, which are the best available materials, have Poisson's ratios approximately equal to $1 / 2$. It is further shown that the method of strain measurement after annealing breaks down when this ratio approaches $1 / 2$.

In this report a new method is described which does not depend on Poisson's ratio and therefore can be used with models made of Fosterite and Bakelite. This method employs frozen stress patterns from normal and oblique incidence. The separation of the principal stresses is obtained by the numerical integration of one of the differential equations of equilibrium in Cartesian coordinates rather than by strain measurement after annealing which involves Poisson's ratio. It will be shown that this permits the determination of all six stress components at each point of a body.

The report consists of three parts. The first part comprises a survey and analysis of the method in three-dimensional photoelasticity which rests on the freezing and slicing processes and strain measurement after annealing. The second part presents the theory of the new method. The third part contains the application of the new method to the determination of stresses in a diametrically compressed sphere.

The investigation was conducted in the Photoelastic Laboratory of the Mechanics Department at the Illinois Institute of Technology under the sponsorship and with the financial assistance of the National Advisory Committee for Aeronautics. The Research Corporation provided the funds for the fellowship held by Mr. Roscoe Guernsey, Jr. Mr. David Landsberg, Assistant Research Engineer in Experimental Stress Analysis, assisted in all experimental phases of the work. It is a pleasure to acknowledge his cooperation. Acknowledgment is also due Mrs. Dora L. Frocht for her assistance in the translation of the paper by Prigorovsky and Preiss (reference 1).

\section{SYMBOLS}

\section{$\sigma_{x}, \sigma_{y}, \sigma_{z}$ \\ normal stresses, psi}

$\tau_{x y}, \tau_{y z}, \tau_{z x}$

$\sigma_{\theta}, \tau_{\theta}$

$p, q$

$p^{\prime}, q^{\prime}$

$p^{\prime \prime}, q^{\prime \prime}$

$n_{x}, n_{y}, n_{z}$

$n_{x y}, n_{y z}, n_{z x}$

$n^{\prime}, n^{\prime \prime}, n^{\prime \prime \prime}$

$n_{\theta_{y},} n_{\theta_{2}}$

$\theta$

$\phi^{\prime}, \phi^{\prime \prime}, \phi^{\prime \prime \prime}$

shearing stresses, psi

stresses on an inclined plane, psi

principal stresses, psi

secondary principal stresses in $X Y$-plane, psi secondary principal stresses in $X Z$-plane, psi normal stresses in fringes

shearing stresses in fringes

fringe orders at normal incidence for slices parallel to $X Y$-plane, $X Z$-plane, and $Y Z$-plane, respectively

fringe orders at oblique incidence for rotations about $Y$-axis and $Z$-axis, respectively angle of rotation of a slice; also angle defining an inclined plane

isoclinic parameters at normal incidence for slices parallel to $X Y$-plane, $X Z$-plane, and $Y Z$-plane, respectively

$\phi_{\theta_{y}} \quad$ isoclinic parameter at oblique incidence for rotation about $Y$-axis

$F \quad$ shear fringe value of slice, psi per fringe

$F^{\prime}, F^{\prime \prime} \quad$ shear fringe value for slices parallel to $X Y$ plane and $X Z$-plane, respectively

shear fringe value for actual light path in slices rotated about $Y$-axis

shear fringe value of material, psi per fringe per inch 


$\epsilon_{x}, \epsilon_{y}, \epsilon_{z}$
$E$
$\nu$
$P$
$A$
$A_{c}$
$R$
$R_{c}$
$\bar{\sigma}_{x}, \bar{\sigma}_{y y}, \bar{\sigma}_{z}$
$\bar{\tau}_{x y}, \bar{\tau}_{y z}, \bar{\tau}_{z x}$
$\sigma_{y y}^{\prime}$
$\tau_{y z}{ }^{\prime}$

\section{SURVEY AND ANALYSIS OF EXISTING METHODS}

FROZEN STRESSES AND OBLIQUE INCIDENCE

Frozen pattern.-It is now well established that elastic stress systems can be fixed or frozen into models made of certain diphase plastics and that such models with frozen stresses can be sliced into thin sections without disturbing the fixed pattern (references 2 to 5 ). Observations of such slices in a polariscope yield the relative retardations as well as the isoclinic parameters at each point of the pattern.

oblique incidence.-The use of oblique incidence of a collimated beam of light, as suggested by Drucker and Mindlin, adds materially to the information obtainable photoelastically (references 6 and 7 ). The retardation and isoclinics at normal incidence are a function of the secondary principal stresses in the plane of the slice, while those at oblique incidence depend on the secondary principal stresses in a plane perpendicular to the wave normal at each point of the slice.

The basic relation for oblique incidence with rotation about the $Z$-axis is given by the following expression

$\left(2 F n_{\theta_{z}}\right)^{2}=\frac{1}{\cos ^{2} \theta_{2}}\left\{\left[\left(\sigma_{x}-\sigma_{z}\right)+\left(\sigma_{y}-\sigma_{x}\right) \sin ^{2} \theta_{z}+\tau_{x y} \sin 2 \theta_{z}\right]^{2}+\right.$
$\left.4\left(\tau_{x z} \cos \theta_{z}+\tau_{y z} \sin \theta_{z}\right)^{2}\right\}$

The system of notation used in this report is shown in figure 1. Normal stresses are positive when tensile and negative when compressive. The four components of shear' in the $X Y$-plane are referred to either as the $\tau_{x y}$ or the $\tau_{y x}$ shear system, and the sign of this system is positive when the shearing components are as shown in figure 1 (reference 8, par. 1.3). Similarly the shear system in the $Y Z$-plane is positive if the components are as shown in figure 1 . No signs are attached to individual shearing stress components, their directions being determined by inspection (reference 8, par. 8.2).

By combining the data from five stress patterns of different obliqueness it is possible to determine the three differences between the normal stress components and the three systems of shearing stresses at each point in the slice (for convenience the plane of the slice is taken as one of the coordinate planes).

It can be shown that from the five quantities obtained with the aid of oblique incidence it is possible in turn to

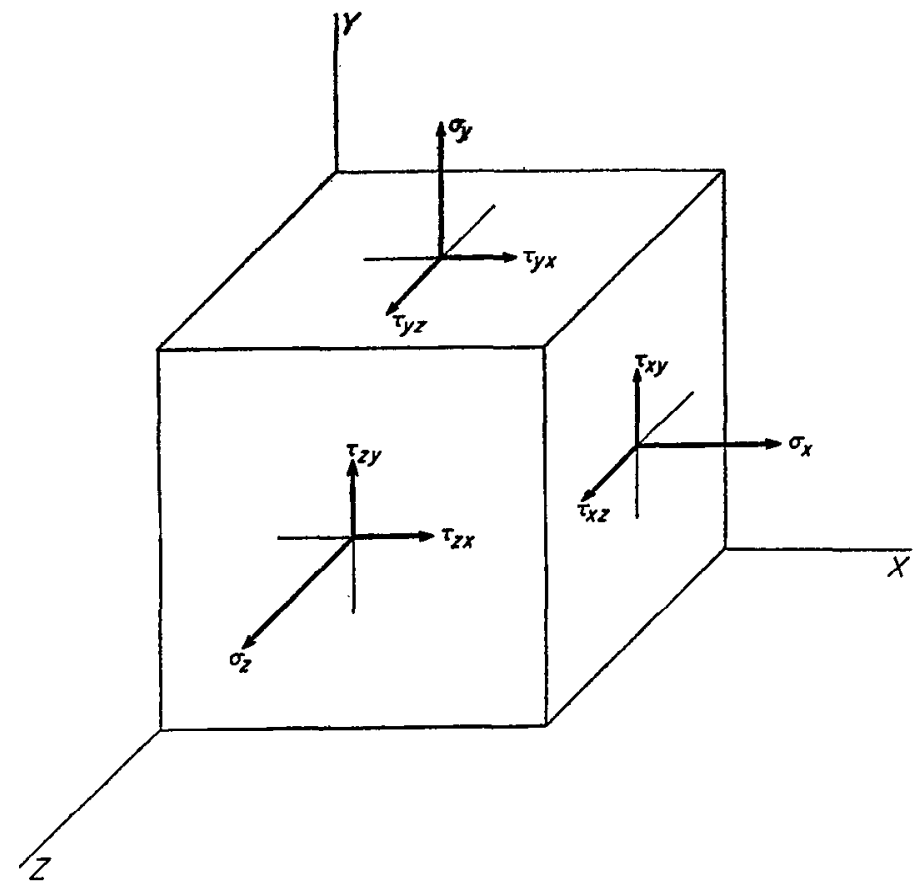

Figure 1.-Positive normal stress components and positive systems of shearing stresses.

obtain the three principal shears at all points of the section. This is equivalent to determining Mohr's circle for a threedimensional state of stress except for its origin which remains indeterminate.

Limitations of purely photoelastic data.-Except for special cases, the optical data by themselves are insufficient for the determination of the individual principal stresses. This limitation results from the fact that isotropic stress systems produce no photoelastic effects. Consequently, two states of stress differing by an arbitrary isotropic system produce equal photoelastic effects.

The method employing scattered light, or the 'Tyndall effect, which was developed in this country by Weller (references 9 and 10) and independently by Menges (reference 11) suffers from the same limitation.

The method of convergent light employed by Hiltscher (reference 12) and by Kuske (reference 13) makes it possible to determine also the directions of the principal stresses but not their magnitudes.

\section{SEPARATION OF PRINCIPAL STRESSES}

Free surfaces,-The limitation mentioned above does not hold at free boundary surfaces. A free surface is subjected to only two principal stresses, similar to those in plane stress systems. Tangential slices yield directly the difference between the principal surface stresses. If in addition a slice is taken normal to the surface and parallel to one principal stress, it is possible to determine the individual principal stresses on the surface (fig. 2). This method has been employed by Leven and Frocht (reference 14) to determine the principal stresses on the surface of Diesel engine valves. Leven (reference 15) has also applied this method to the 


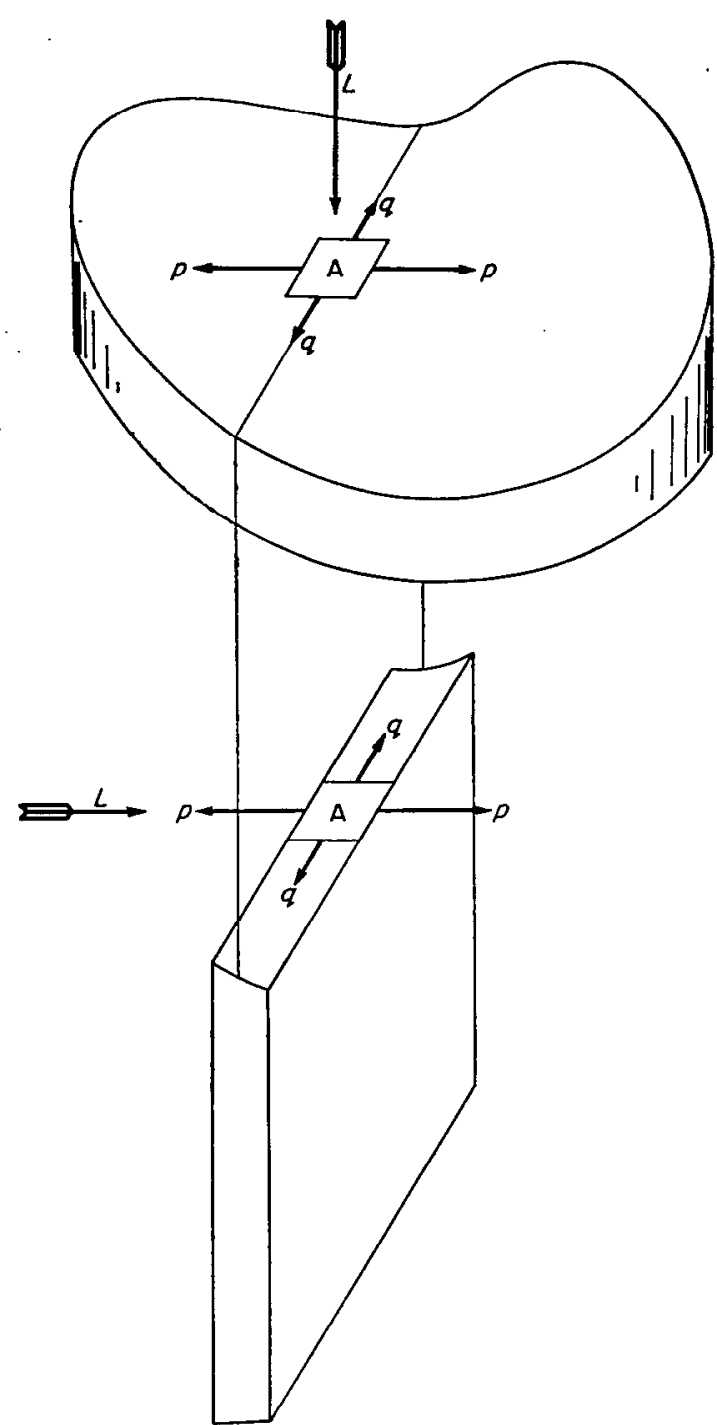

Figure 2.-Slices and directions of light for determination of surface stresses. $L$, direction of light.

problem of surface stresses in torsion, and Hetényi (reference 16) has applied it to threaded connections. In these applications the faces of the slice were oriented to be normal to the direction of a collimated polarized beam.

In special cases the combination of oblique and normal incidence leads to a complete determination of the principal stresses. Using this combination, the stress distribution in Saint Venant torsion was determined (reference 17).

Planes of symmetry.-For the special case where a plane of symmetry exists Jessop (reference 18) has developed an extension of the Lamé-Maxwell equations (Filon's graphical integration) to three-dimensional cases. By means of these extended equations it is possible to determine the stresses along the axis of symmetry. However, the method lacks generality.

Strain measurement after annealing.-It has been suggested by Kuske (reference 5) that mechanical strain measurements after annealing in conjunction with the freezing method might be used to provide the additional relation necessary for the determination of the principal stresses at a general point. If it be assumed that the differences between the three normal stress components at a point have been found photoelastically from equation (1), there result:

$$
\left.\begin{array}{l}
\sigma_{z}-\sigma_{y}=C_{z y} \\
\sigma_{y}-\sigma_{x}=C_{y x} \\
\sigma_{z}-\sigma_{x}=C_{z x}
\end{array}\right\}
$$

where the $C$ 's represent constants. If now the slice from the model containing the frozen stresses is annealed, the state of stress is relieved and the thickness of the slice at each point will return to its original unstressed value. From this change in thickness, if it can be measured with accuracy, the strain at a point in a direction perpendicular to the slice can be computed. Taking this direction as the $Z$-axis, for instance, the strain would be $\epsilon_{z}$. Then from Hooke's law,

$$
\epsilon_{z}=\frac{1}{E}\left[\sigma_{z}-\nu\left(\sigma_{x}+\sigma_{y}\right)\right]
$$

which may be written as

$$
\epsilon_{z}=\frac{1}{E}\left[(1-2 \nu) \sigma_{z}+\nu\left(\sigma_{z}-\sigma_{y}\right)+\nu\left(\sigma_{z}-\sigma_{x}\right)\right]
$$

from which

$$
\sigma_{z}=\frac{F_{i} \epsilon_{z}-\nu\left(\sigma_{z}-\sigma_{y}\right)-\nu\left(\sigma_{z}-\sigma_{x}\right)}{1-2 \nu}
$$

In view of equations (2) this gives the stress component $\sigma_{z}$ after which $\sigma_{x}$ and $\sigma_{y}$ are readily found. The entire state of stress has thus been determined.

\section{LIMITATIONS OF MECHANICAL STRAIN MEASUREMENT}

Poisson's ratio equal 1/2. - The method outlined above would seem to solve the problem and offer a powerful method. of attack. Closer examination discloses certain serious difficulties. For the photoelastic materials used in this country, such as Fosterite and Bakelite, Poisson's ratio is very nearly $1 / 2$ at the elevated temperatures used in the freezing process, and for this value of $\nu$ the method breaks down.

Thus, inspection of the general equations of Hooke's law

$$
\left.\begin{array}{l}
\epsilon_{x}=\frac{1}{E}\left[\sigma_{x}-\nu\left(\sigma_{y}+\sigma_{z}\right)\right] \\
\epsilon_{y}=\frac{1}{E}\left[\sigma_{y}-\nu\left(\sigma_{z}+\sigma_{x}\right)\right] \\
\epsilon_{z}=\frac{1}{E}\left[\sigma_{z}-\nu\left(\sigma_{x}+\sigma_{y}\right)\right]
\end{array}\right\}
$$

shows that when $\sigma_{x}=\sigma_{y}=\sigma_{z}$, that is, when the stresses form an isotropic system, and, in addition, the value of Poisson's ratio $\nu$ is $1 / 2$, then

$$
\epsilon_{x}=\epsilon_{y}=\epsilon_{z}=0
$$


In other words, isotropic systems of stresses produce no strains. Hence, two stress systems differing by an arbitrary isotropic system produce the same strains. Thus, when Poisson's ratio is $1 / 2$ a given strain field does not determine a unique stress field, although the converse is not true. Strain measurement when $\nu=1 / 2$ thus adds nothing to the general solution of the three-dimensional problem.

Poisson's ratio nearly 1/2.--If Poisson's ratio is slightly less than $1 / 2$, the method of strain measurement after annealing should theoretically lead to a solution. However, other difficulties arise. Equation (4a) may be written as

$$
\sigma_{z}=\frac{E \epsilon_{z}-\nu\left(C_{z y}+C_{z x}\right)}{1-2 \nu}
$$

If $\nu$ is the true value of Poisson's ratio and $\nu+\Delta \nu$ is its experimentally determined value, then the error $\Delta \sigma_{z}$ in the computed stress $\sigma_{z}{ }^{\prime}=\sigma_{z}+\Delta \sigma_{z}$ for a measured $\epsilon_{z}$ is

$$
\sigma_{z}^{\prime}-\sigma_{z}=\Delta \sigma_{z}=\frac{\Delta \nu}{1-2 \nu-2 \Delta \nu}\left(\sigma_{x}+\sigma_{y}\right)
$$

With $\nu$ very close to $1 / 2$, a. very small error $\Delta \nu$ in Poisson's ratio may lead to large errors $\Delta \sigma_{z}$ in the computed stress. For instance, if $\nu=0.48$ is assumed, which is the approximate value for Fosterite, and $\Delta \nu$ is taken as only 0.01 , then

$$
\Delta \sigma_{z}=\frac{0.01}{0.02}\left(\sigma_{x}+\sigma_{y}\right)=0.50\left(\sigma_{x}+\sigma_{y}\right)
$$

Experimental measurements of $\nu$-Experiments with the determination of Poisson's ratio for Fosterite and similar plastics indicate that it will be rather difficult to determine the value of $\nu$ closer than \pm 5 percent. The error $\Delta \sigma_{2}$ in equation ( $6 \mathrm{~b}$ ) would be particularly large when $\sigma_{x}$ and $\sigma_{u}$ happen to be of the same sign and each is large in comparison with $\sigma_{z}$. All things considered, no great accuracy can be expected from this method so long as Poisson's ratio is nearly $1 / 2$.

It must be pointed out, however, that strain measurements may serve a useful purpose. Assuming that, in some way or other, the normal stress components have been found, the strains can be calculated and compared with those found experimentally. Here the error in the computed strains due to an error in Poisson's ratio is given by

$$
\Delta \epsilon_{z}--\frac{1}{E}\left(\sigma_{x}+\sigma_{\nu}\right) \Delta \nu
$$

which is not large.

\section{Method SUgGested BY PRIgorovsKy AND PREISS}

The method outlined above for the separation of the principal stresses which employs oblique and normal incidence of collimated polarized light and strain measurement after annealing is not the only possible procedure. Prigorovsky and Preiss suggest two alternative methods in reference 1. Their procedures combine (1) stress patterns from normal and oblique incidence with (2) axis patterns from convergent polarized light and (3) strain measurements after annealing. The significant point lies in the fact that their method utilizes strain measurement after annealing and therefore breaks down when Poisson's ratio equals $1 / 2$.

\section{THEORY OF SHEAR DIFFERENCE METHOD}

General theory.-A method for determining stresses in three-dimensional problems is now proposed which is completely general. With this method the six stress components at any point may be found. It is essentially an extension to three dimensions of the method, long and effectively used for plane problems, which is known as the shear difference method (reference 8 , ch. 8).

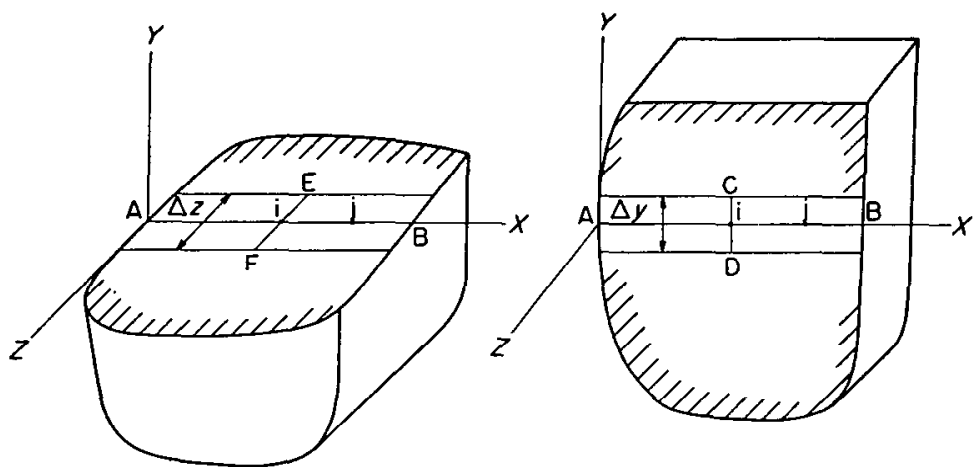

FIGURE 3.-Auxiliary lines in $X Y$-and $X Z$-plancs for shear difference method.

Consider an arbitrarily loaded unsymmetrical model with the set of coordinate axes as shown in figure 3 . Let a straight line $A B$ be drawn through point $i$ from boundary to boundary and let this line be taken as the $X$-axis. At any point along this line the first differential equation of equilibrium, with body forces neglected, is

$$
\frac{\partial \sigma_{x}}{\partial x}+\frac{\partial \tau_{y x}}{\partial y}+\frac{\partial \tau_{z x}}{\partial z}=0
$$

and upon integration the stress at any point $\mathbf{j}$ is given by

$$
\left(\sigma_{x}\right)_{j}=\left(\sigma_{x}\right)_{a}-\int_{a}^{j} \frac{\partial \tau_{y x}}{\partial y} d x-\int_{a}^{j} \frac{\partial \tau_{z x}}{\partial z} d x
$$

where $\left(\sigma_{x}\right)_{a}$ denotes the stress at point $\mathrm{A}$ and $\left(\sigma_{x}\right)_{j}$, the stress at any other point $\mathrm{j}$ on the line $\mathrm{AB}$. The partial derivative $\partial \tau_{y x} / \partial y$ is the rate of change of $\tau_{y x}$ with respect to $y$ and $\partial \tau_{z x} / \partial z$ is the rate of change of $\tau_{z x}$ with respect to $z$. Thus if values of $\tau_{y x}$ were computed along a line through i parallel to the $Y$-axis and the curve $\tau_{y x}=f(y)$ were plotted, then $\left(\frac{\partial \tau_{y x}}{\partial y}\right)_{i}$ would be the slope of the curve $f(y)$ at point $i$. Similarly $\left(\frac{\partial \tau_{z x}}{\partial z}\right)_{i}$ is the slope of the curve $\tau_{z x}=g(z)$ at point $\mathrm{i}$. As in the plane problem, these slopes may be approximated by computing the shearing stresses at points near $i$ on opposite sides of the line $\mathrm{AB}$ and forming finite difference quotients. Thus, choosing neighboring points $\mathrm{C}$ and $\mathrm{D}$ in the $X Y$-plane and similarly points $\mathrm{E}$ and $\mathrm{F}$ in the $X Z$-plane, 


$$
\begin{aligned}
& \left(\frac{\partial \tau_{\nu x}}{\partial y}\right)_{i} \doteq \frac{\left(\tau_{y x}\right)_{C}-\left(\tau_{y x}\right)_{D}}{\Delta y}=\left(\frac{\Delta \tau_{y x}}{\Delta y}\right)_{i} \\
& \left(\frac{\partial \tau_{z x}}{\partial z}\right)_{i} \doteq \frac{\left(\tau_{z x}\right)_{F}-\left(\tau_{z x}\right)_{E}}{\Delta z}=\left(\frac{\Delta \tau_{z x}}{\Delta z}\right)_{i}
\end{aligned}
$$

Thus if the shearing stresses can be determined along four auxiliary lines, parallel to and on opposite sides of $\mathbf{A B}$, two lines in the $X Y$-plane and two in the $X Z$-plane, one has all the data necessary to obtain the quotients on the right side of equations (10) and hence good approximations to the partial derivatives. In evaluating equations (10), care must be taken to attach the proper signs to the shear systems $\tau_{y x}$ and $\tau_{z x}$, as in figure 1 .

Substituting the above approximations for the partial derivatives in equation (9) and replacing the integrals by summations, the following equation is obtained:

$$
\left(\sigma_{x}\right)_{j}=\left(\sigma_{x}\right)_{a}-\sum_{n}^{j} \frac{\Delta \tau_{y x}}{\Delta y} \Delta x-\sum_{a}^{j} \frac{\Delta \tau_{z x}}{\Delta z} \Delta x
$$

The summations are evaluated graphically in the same manner as in plane problems. For convenience, $\Delta y$ and $\Delta z$ may be taken numerically equal to $\Delta x$. Then equation (11a) becomes

$$
\left(\sigma_{x}\right)_{J}=\left(\sigma_{x}\right)_{a} \pm \sum_{a}^{j} \Delta \tau_{u x} \pm \sum_{a}^{j} \Delta \tau_{z x}
$$

in which $\Delta \tau_{y x}$ and $\Delta \tau_{z x}$ have the mean value in each interval $\Delta x$.

Shearing stresses in first slice.-In order to carry out this integration, it is necessary to determine the magnitude and direction of shearing stresses $\tau_{y x}$ along the two auxiliary lines in the $X Y$-plane and of $\tau_{z x}$ along the two auxiliary lines in the $X Z$-plane. The shearing stresses $\tau_{y x}$ are obtained from a slice in the $X Y$-plane containing $\mathrm{AB}$ in its middle surface. The stress pattern of this slice from normal incidence will give the difference between the secondary principal stresses in the plane of the slice at all points, and the corresponding isoclinics furnish their orientation. The magnitude of the shearing stress $\tau_{y x}$ at any point will then be given by

$$
\tau_{\nu x}=\frac{1}{2}\left(p^{\prime}-q^{\prime}\right) \sin 2 \phi^{\prime}
$$

where $p^{\prime}$ and $q^{\prime}$ are the secondary principal stresses in the $X Y$-plane and $\phi^{\prime}$ is the isoclinic parameter. The directions are determined by inspection as in paragraph 8.2 of reference 8. Using equation (12a), the shearing stresses $\tau_{y x}$ along the auxiliary lines and along $A B$ itself may be found.

Shearing stresses in second slice.-A second slice lying in the $X Z$-plane and containing line $\mathrm{AB}$ would furnish similar information for $\tau_{z x}$. Here a practical difficulty arises since the first slice removes an essential part of the second slice. One of several procedures may be used to eliminate this difficulty.

(1) In the general case two identical models, identically loaded, may be used, one for the $X Y$ slice and one for the $X Z$ slice. The shearing stresses $\tau_{y x}$ for the $X Y$ slice are calculated from equation (12a). Similarly, the shearing stresses $\tau_{z x}$ for the $X Z$ slice are given by

$$
\tau_{z x}=\frac{1}{2}\left(p^{\prime \prime}-q^{\prime \prime}\right) \sin 2 \phi^{\prime \prime}
$$

where $p^{\prime \prime}$ and $q^{\prime \prime}$ are the secondary principal stresses and $\phi^{\prime \prime}$ is the isoclinic parameter in the $X Z$ slice.

(2) In large models it may be possible to use a sub slice from the main slice for determining $\tau_{z x}$. After the data are obtained from the main slice, a small section containing the line $A B$ is cut from it, as shown in figure 4 (a). The necessary data in the $X Z$-plane are then obtained from normal incidence on the sub slice, as shown. This procedure is feasible if the model is large so that the main slice can be made of sufficient thickness.

(3) In the particular case where a plane of stress symmetry exists, such as the $X Y$-plane in figure 4 (b), advantage can be taken of this symmetry. Referring to figure 4 (b), let it
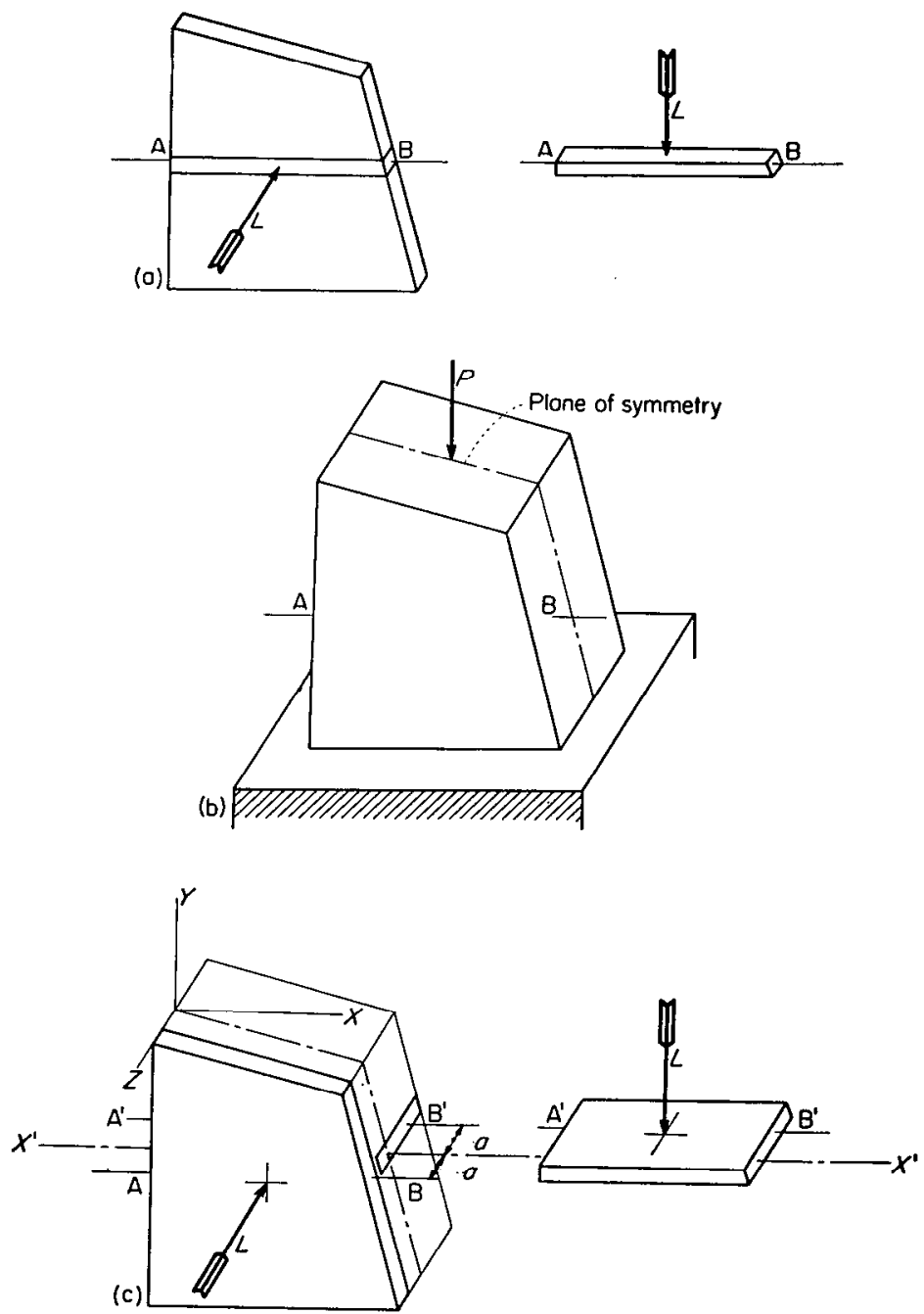
(a) Sub slice.
(b) Loaded model.
(c) Slices from opposite sides of plane of symmetry.

Frgure 4.-Schematic diagram of necessary slices. 
be assumed that the stresses on line $A B$ pare required. The first slice is made parallel to the $X Y$-plane and contains the line $\mathrm{AB}$ as shown in figure 4 (c). The orthogonal slice is cut from the opposite side of the body so that it contains the symmetrically placed line $\mathrm{A}^{\prime} \mathrm{B}^{\prime}$, along which the stresses are the same as along $\mathrm{AB}$ itself. The necesspary shearing stresses are calculated as outlined in procedure, $(1)$, above.

Normal stresses. - The starting value $\left(\sigma_{x}\right)_{a}$ will be obtained from boundary conditions and boundary fringe orders. The intcgration may then be carried out and values of $\sigma_{x}$ obtained along AB. Further, from Mohr's circle or other considerations:

$$
\begin{gathered}
\left(\sigma_{x}-\sigma_{\nu}\right)_{j}=\left(p^{\prime}-q^{\prime}\right)_{j} \cos 2 \phi_{j}^{\prime}=2 F^{\prime} n^{\prime}{ }_{j} \cos 2 \phi^{\prime}{ }_{j} \\
\left(\sigma_{x}-\sigma_{z}\right)_{j}=\left(p^{\prime \prime}-q^{\prime \prime}\right)_{j} \cos 2 \phi^{\prime \prime}{ }_{j}=2 F^{\prime \prime} n^{\prime \prime}{ }_{j} \cos 2 \phi^{\prime \prime}{ }_{j}
\end{gathered}
$$

where the $F$ 's and $n$ 's denote, respectively, fringe value of the model in shear and fringe order at point $j$. From equations (13a) and (13b)

$$
\begin{gathered}
\left(\sigma_{y}\right)_{j}=\left(\sigma_{x}\right)_{j}-\left(p^{\prime}-q^{\prime}\right)_{j} \cos 2 \phi^{\prime}{ }_{j} \\
\left(\sigma_{z}\right)_{j}=\left(\sigma_{x}\right)_{j}-\left(p^{\prime \prime}-q^{\prime \prime}\right)_{j} \cos 2 \phi^{\prime \prime}{ }_{j}
\end{gathered}
$$

All the necessary data for the evaluation of $\left(\sigma_{y}\right)_{j}$ and $\left(\sigma_{z}\right)_{j}$ are obtained from the slices in the $X Y$ - and $X Z$-planes, respectively.

Use of oblique incidence.-At this stage five of the six stress components, namely $\sigma_{x}, \sigma_{y}, \sigma_{z}, \tau_{y x}$, and $\tau_{z x}$, have been found at all points of $\mathrm{AB}$. There remains one unknown stress component $\tau_{y z}$. The shear system $\tau_{y z}$ has no influence on the stress patterns from normal incidence for either one of the slices but will have an effect on the patterns from oblique incidence.

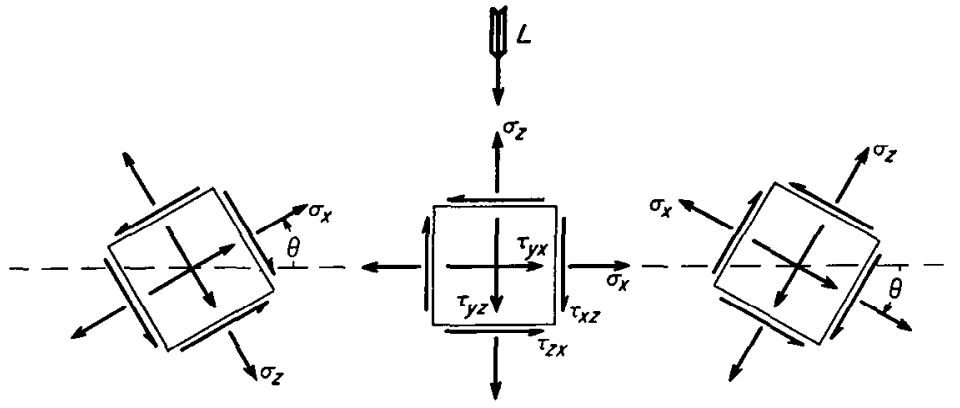

Figure 5.-Normal incidence and oblique incidence for different directions of rotation.

In order to find the shear system $\tau_{y^{2}}$ an oblique stress pattern is obtained from either one of the two slices. For concreteness assume that the slice parallel to the $X Y$-plane is used and that it is rotated in a clockwise direction about the $Y$-axis through an arbitrary angle $\theta_{y}$. Figure 5 shows a view of a small element as seen from the positive end of the $Y_{\text {-axis. }}$ From equation (1) the fringe order $n_{\theta y}$ at any point due to the oblique incidence is given by

$2 F_{\theta y} n_{\theta y}=\sqrt{\left[\sigma_{y}-\left(\sigma_{x} \cos ^{2} \theta_{y}+\sigma_{z} \sin ^{2} \theta_{y}-\tau_{z x} \sin 2 \theta_{y}\right)\right]^{2}+}$
$4\left(\tau_{y x} \cos \theta_{y}-\tau_{y z} \sin \theta_{y}\right)^{2}$

in which $\sigma_{x}, \sigma_{y}$, and $\sigma_{z}$ are the known normal stresses and $\tau_{y x}$ and $\tau_{z x}$ are the known shear systems. Also the isoclinic parameter $\phi_{\theta}$ for the oblique incidence is given by the expression

$$
\sin 2 \phi_{\theta y}=\frac{\tau_{y z} \cos \theta_{y}-\tau_{y z} \sin \theta_{y}}{F_{\theta_{y}} n_{\theta_{y}}}
$$

If the rotation about the $Y$-axis be made in the counterclockwise direction then

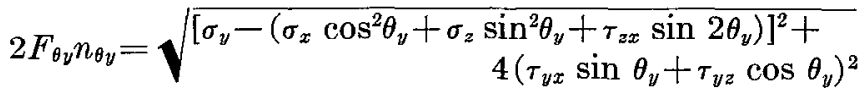

and

$$
\sin 2 \phi_{\theta y}=\frac{\tau_{y z} \cos \theta_{y}+\tau_{y x} \sin \theta_{y}}{F_{\theta_{y}} n_{\theta y}}
$$

Similar equations may be written for rotation of the slice parallel to the $X Z$-plane about the $Z$-axis.

It is to be noted that in general the retardation observed at any point depends on the direction of rotation of the slice. For one direction of rotation the fringe order at a point will be different, from its value for the other direction. In the particular case when the slice contains a principal plane, then $\tau_{z x}=\tau_{z y}=0$ and equations (14a) and (14b) become identical. In such cases the direction of rotation is immaterial. In dealing with general slices it is important to note carefully the direction of rotation relative to the wave normal and to attach the proper signs to all the stresses.

Each of equations (14a), (14b), (15a), and (15b) may be solved for the unknown shear system $\tau_{y z}$. It is necessary only to determine the fringe order and the isoclinic parameter $\phi_{\theta y}$ along the line $A B$. If the rotation is counterclockwise equation (14b) or (15b) is appropriate. Of these, equation $(15 \mathrm{~b})$ is much the simpler. Using equation (15b) and $\theta=45^{\circ}$ there is obtained

$$
\tau_{y z}=\sqrt{2} F_{\theta_{u}} n_{\theta y} \sin 2 \phi_{\theta y}-\tau_{y x}
$$

With this, $\tau_{y z}$ is easily computed. All six components of stress are thus determined for the point $i$, and therefore the principal stresses themselves are determined at the given point.

Extension to the plastic state.- It should be noted that the method described in this report is not limited to a linear stress-optic law. With minor modifications, which are stated below, the method is equally valid for a nonlinear stress-optic law. Thus, the method is applicable not only to the elastic state but also to the plastic state of the model. This follows from the fact that the only equations, in addition to the stress-optic law, are the equations of equilibrium which are independent of stress-strain relations.

In order to adapt the equations to a nonlinear stress-optic law it is necessary to observe that whereas in the linear range fringes can be used as the unit of stress, since the stress is proportional to the fringe order, in the nonlinear range fringes cannot serve as the unit of stress, since proportionality between stress and birefringence no longer exists. 'To obviate this difficulty all fringe orders in the equations should be converted into standard units, say pounds per square inch, as was done in all preceding equations. 
Now, let the nonlinear stress-optic law be given by

$$
\tau_{m a x}=(p-q) / 2=\tau(n)
$$

where $\tau(n)$ is a known function of $n$. If one replaces the products $F \times n$ by $\tau(n)$ in equations (14) and (15) these equations are directly applicable to a nonlinear stress-optic law. It should, however, be noted that the results will apply to the model only and are not directly transferable to the prototype. It is also observed that the photoelastic models are assumed to be free from strain-hardening.

Effect of Poisson's ratio.-In conclusion, it should be noted that in transferring the results from three-dimensional photoelastic models to metal prototypes the effect of Poisson's ratio will have to be considered. It is fortunate, as shown by the theoretical solutions obtained to date, that the effect of Poisson's ratio on the most significant stresses is small (references 19 and 20).

\section{APPIICATION OF SHEAR DIFFERENCE METHOD TO A DIAMETRICALLY COMPRESSED SPHERE}

DESCRIPTION OF APPARATUS

The apparatus used in this investigation consisted of the following items:

(1) An electric furnace with temperature controls and built-in loading frame with special jigs

(2) An 8-inch photoelastic polariscope with a special immersion tank

(3) An oblique incidence jig

(4) A Babinet-Soleil compensator

A photograph of the electric furnace is shown in figure 6 . This is a relatively large oven 46 inches high, 42 inches wide, and 19 inches deep. It is fitted with automatic temperature controls by means of which any desired thermal cycle could be imposed on the model. The furnace was equipped with a built-in loading frame suitable for the application of all basic types of loading.

A special loading jig built for the investigation is shown in figure 7. It consisted of a smooth circular shaft about $1 / 2$ inch in diameter passing through a pair of smooth, lubricated guide holes carefully alined so that the axis of the shaft was perpendicular to the base. The load was applied to the top

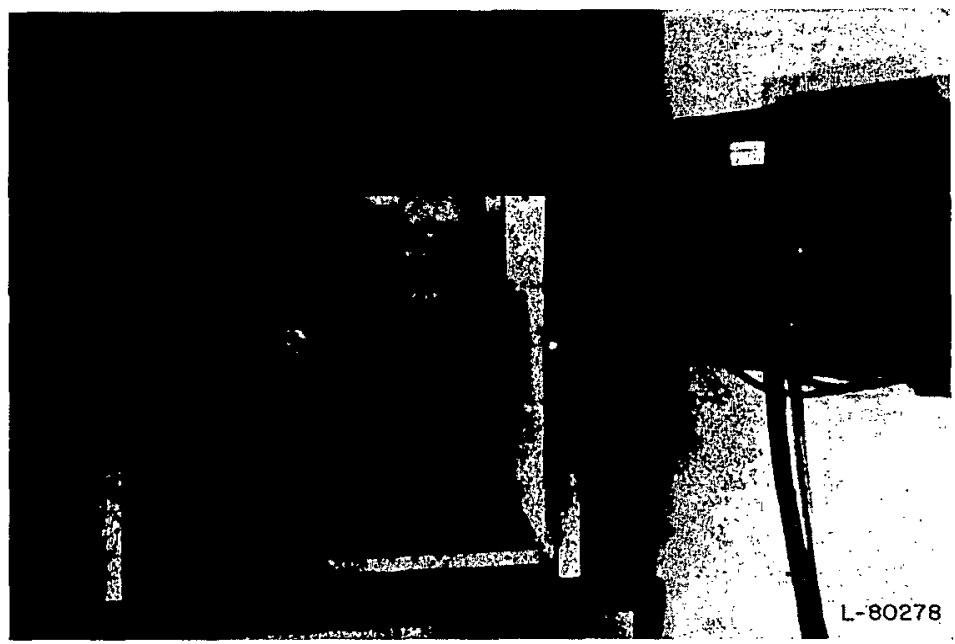

Figure 6.--Electrio furnace and control panel.

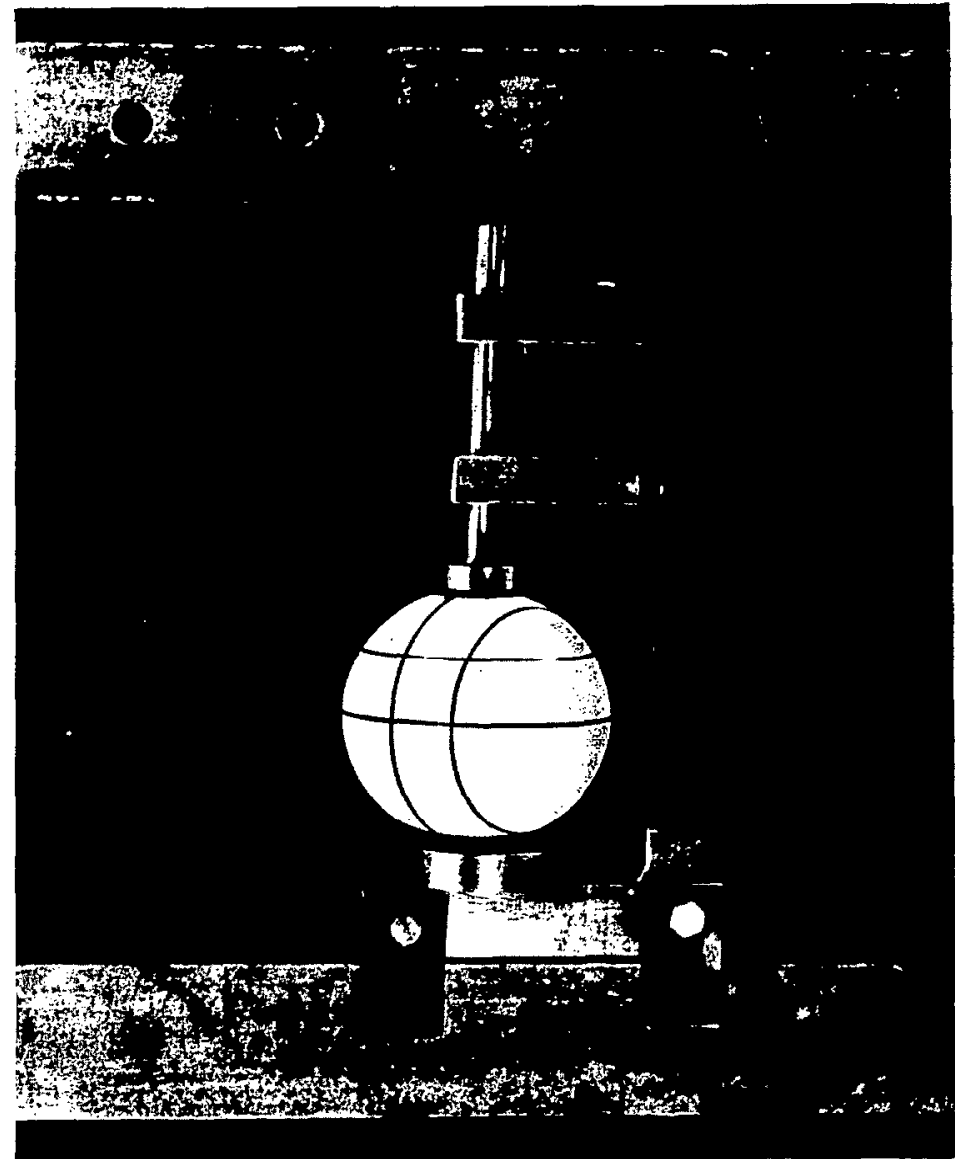

Figure 7.-Loading jig and model of sphere.

of the shaft through a hard steel ball. This jig was found to give almost perfect vertical loading and the friction was negligible.

A special jig was also built for oblique incidence. The frame of the jig can be rotated about a vertical axis through any desired angle which can easily be measured to one-tenth of a degree. The slice was mounted in the frame of the jig and the whole unit was placed in an immersion tank with a suitable mixture of Halowax and mineral oil.

The remaining equipment was standard apparatus in photoelastic laboratories, the descriptions of which are available in the literature.

\section{TEST PROCEDURE}

Model.-The sphere was machined from a cylinder of Fosterite which was proviously annealed to reduce initial stresses. The machining was carried out in a lathe. The rough cylinder of Fosterite was first turned to a true cylinder. In order to form the sphere a tool bit was set in a special jig riding on the carriage of the lathe. This bit could be rotated about a vertical axis lying in the plane of the lathe centers. The cutting was performed by swinging the tool bit by hand around its vertical axis while the cylinder was rotating, and the radius of the sphere was slowly reduced by bringing the tool bit gradually closer to its axis. In this way it was possible to shape the complete sphere except for a relatively small nipple near the chuck. The final diameter of the sphere was $3.313 \pm 0.002$ inches. 
Loading.-The sphere was placed in the loading jig and carefully alined for diametral compressive loading. The model was then heated to $162^{\circ} \mathrm{F}$ in the electric furnace, the rate of heating being about $10^{\circ} \mathrm{F}$ per hour. A load of 172 pounds was then applied to the model. After a soaking period of about 2 hours the temperature was lowered at the rate of $4^{\circ} \mathrm{F}$ per hour to room temperature. The final diameter of the equatorial plane was found to be 3.334 inches and the load axis was measured as 3.102 inches. Although relatively large deformations were developed in the loaded regions, the main body of the sphere was not notably distorted from its original shape. Tho stress pattern of the whole sphere in figure 8 shows that the loads and the stresses were rotationally symmetrical.

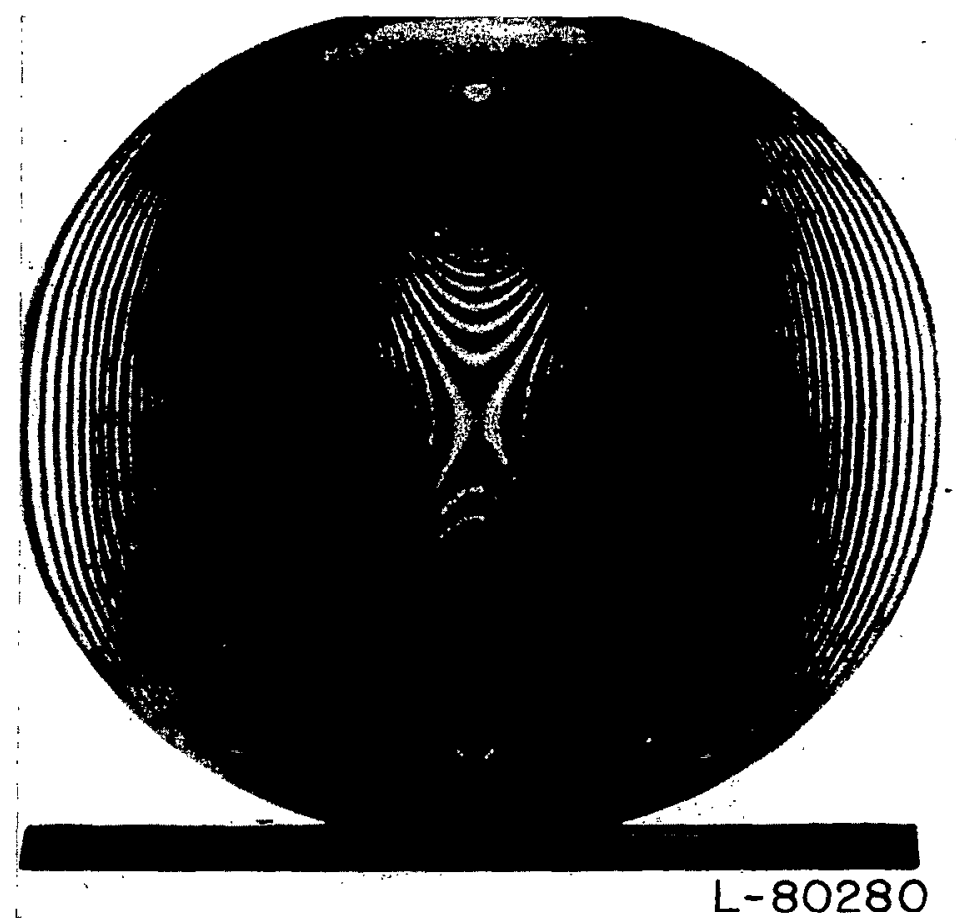

FIGURe 8.--Stress pattern of whole sphere.

Slicing.-In preparation for slicing the center lines of all the slices were carefully scribed on the sphere using the flat spots in the loaded regions as datum planes. The slices were then sawed out roughly on a bandsaw to a thickness of about $3 / 8$ inch. They were subsequently ground by hand to about $1 / 8$-inch thickness in most cases. Great care was taken to keep the slices symmetrical with respect to their center lines.

Figure 9 shows the slicing plan. The first slice removed was parallel to the equator and midway between the equator and the load point. Then from the opposite side of the sphere a meridian slice was removed. Next a slice containing the equatorial plane was cut. Finally a slice parallel to the meridian slice and halfway out on the radius was removed.

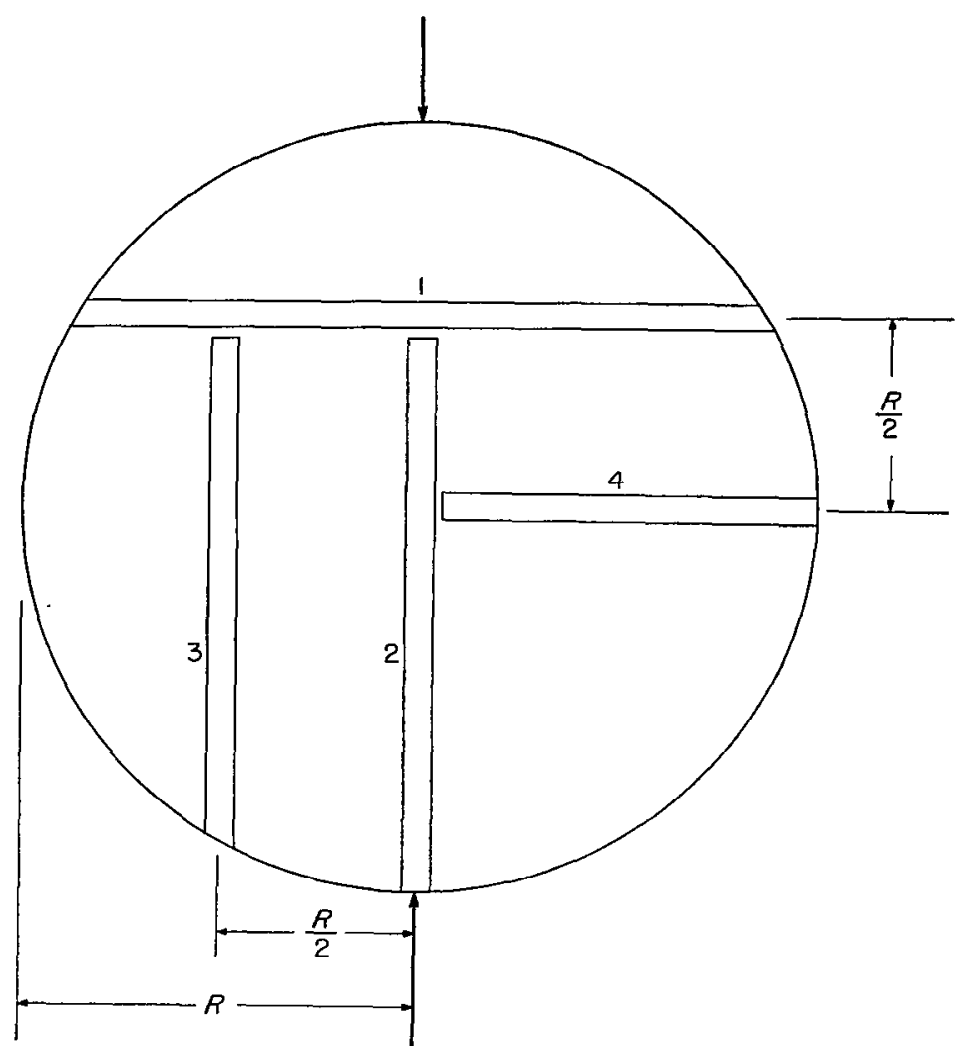

Figure 9.-Slicing plan for sphere. 1, slice parallel to equator; 2, meridian slice; 3 , slice parallel to meridian; and 4, equatorial slice.

Stress patterns and isoclinics.-The slices were mounted in the oblique incidence jig and stress patterns at normal and oblique incidence werc recorded photographically. Typical stress patterns are shown in figures 10 to 15 . Most of the normal incidence patterns show very few fringes. In order to obtain accurate data in these cases a Babinet-Soleil compensator was used to obtain the fringe-order distribulion along the lines of interest by point-by-point exploration.

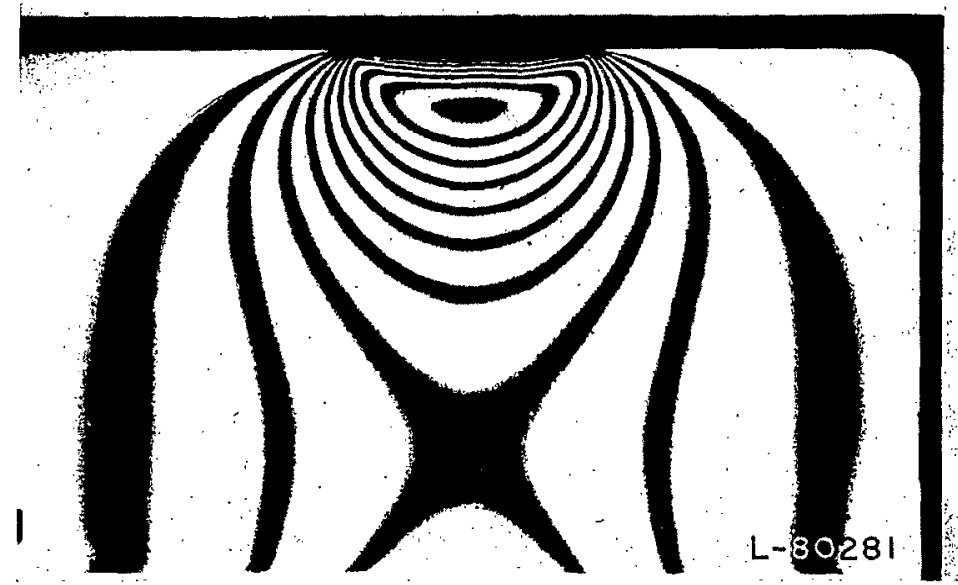

Figure 10. - Stress pattern of meridian slice at normal incidence. 


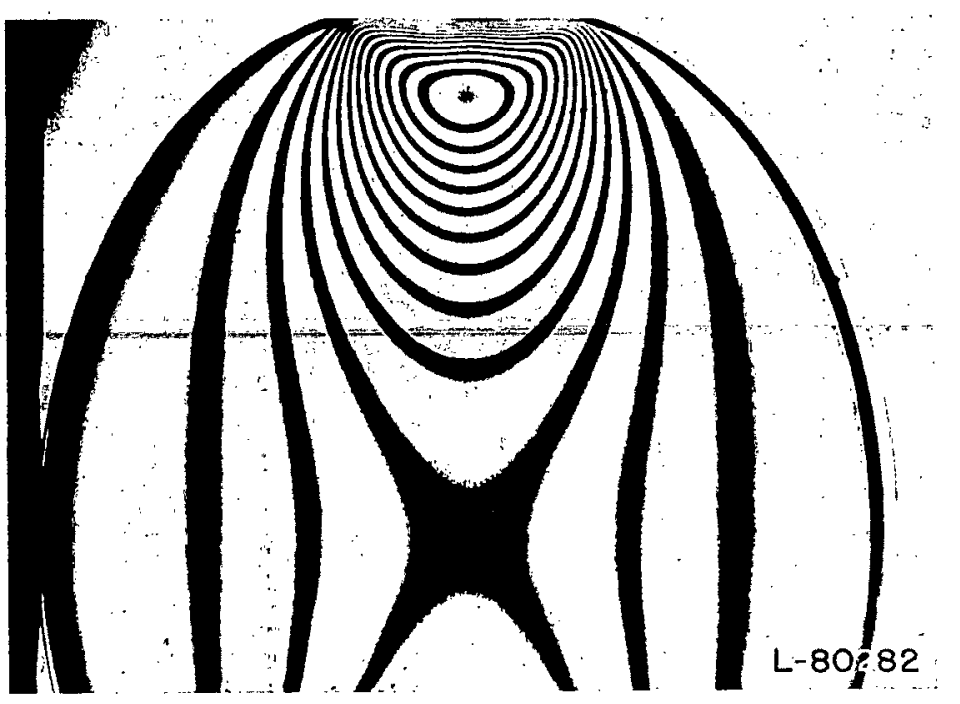

Figure 11.-Stress attern of meridian slice for a rotation of $45^{\circ}$ about $Y$-axis.

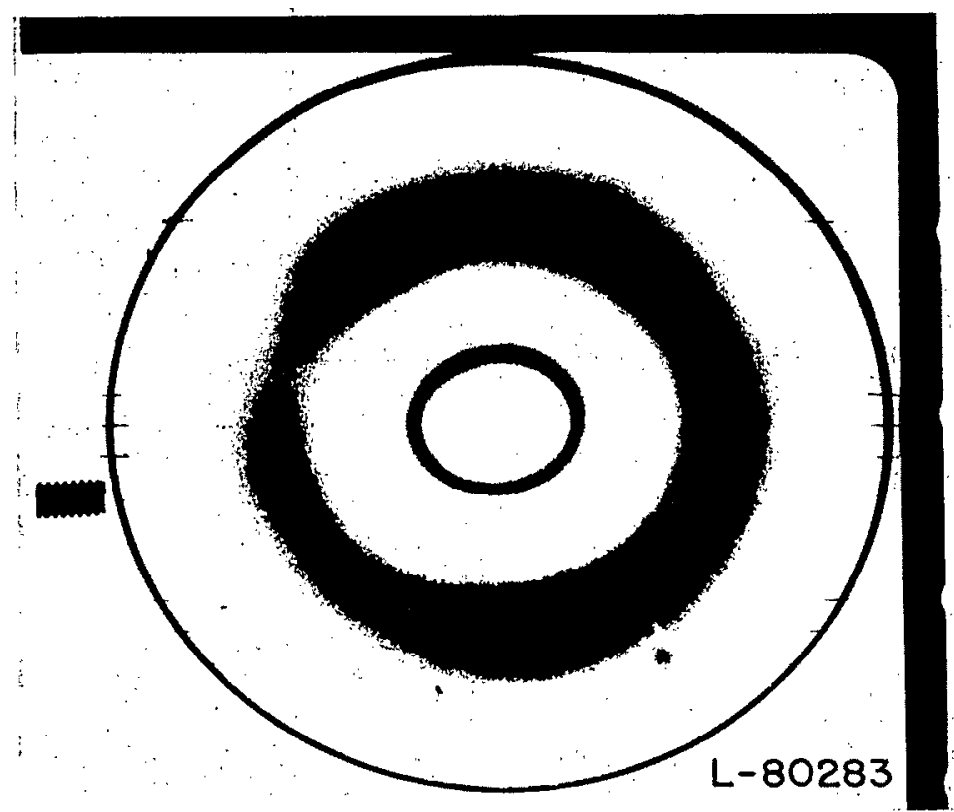

FIGURE 12.-Stress pattern of slice parallel to equator at normal incidence.

A black cross was made on the screen to mark the point on which attention should be centered. The model slice was then adjusted until the line of interest on the image ran true on the intersection of the cross as the straining frame was moved laterally. Then beginning at the outer edge and moving the straining frame by a known amount after each observation the fringe order was obtained at a series of points along the line. From these data the curve of fringeorder distribution was plotted.

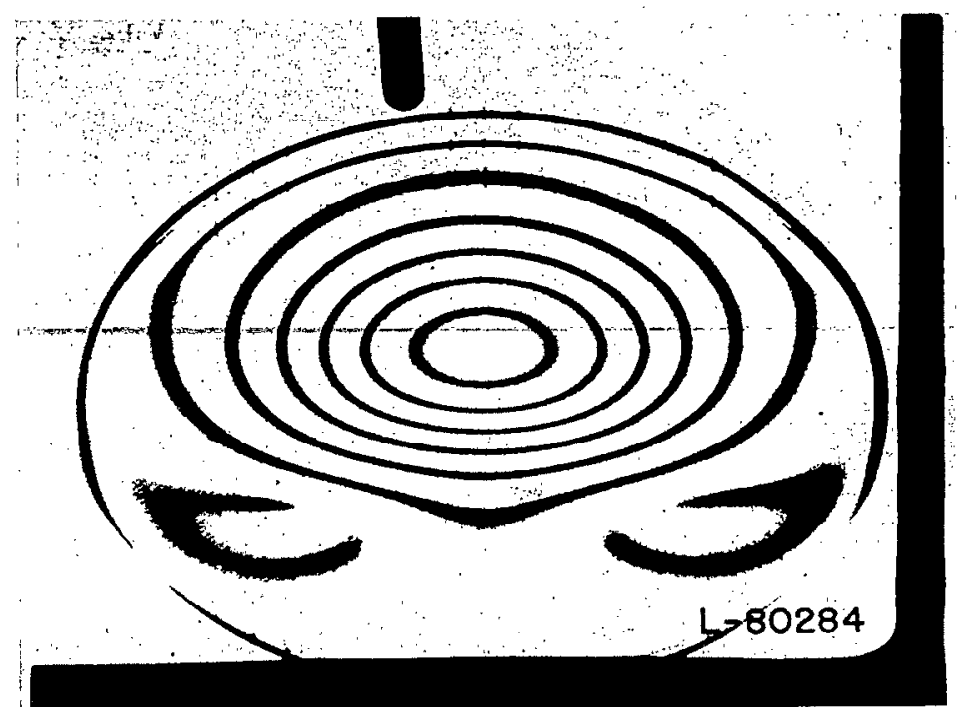

FIGURE 13.-Stress pattern of slice paraliel to equator for a rotation of $45^{\circ}$ about $X$-axis.

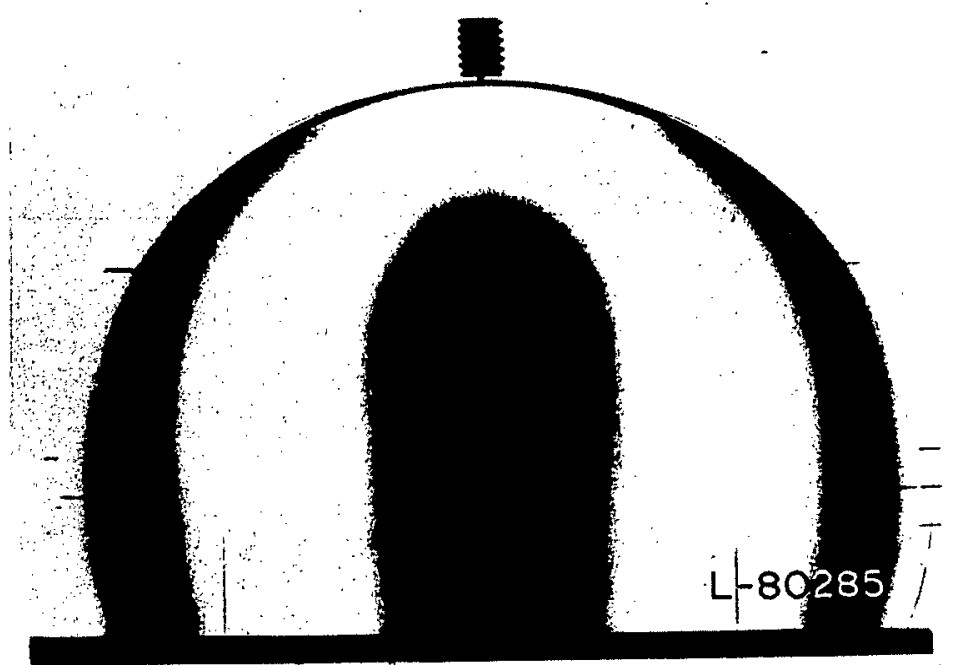

FIGURE 14.-Stress pattern of slice parallel to meridian at normal incidence.

It may be noted that fractional fringe orders can also be obtained by the Tardy method of compensation, the accuracy being comparable with that of the Babinet-Soleil compensator.

Isoclinic lines were recorded by one of two methods. For the over-all picture the isoclinic lines were photographed in most cases (figs. 16 and 17). From the photographs averaged skctches were prepared and used in making the calculations. On several lines direct sketching of the isoclinics 


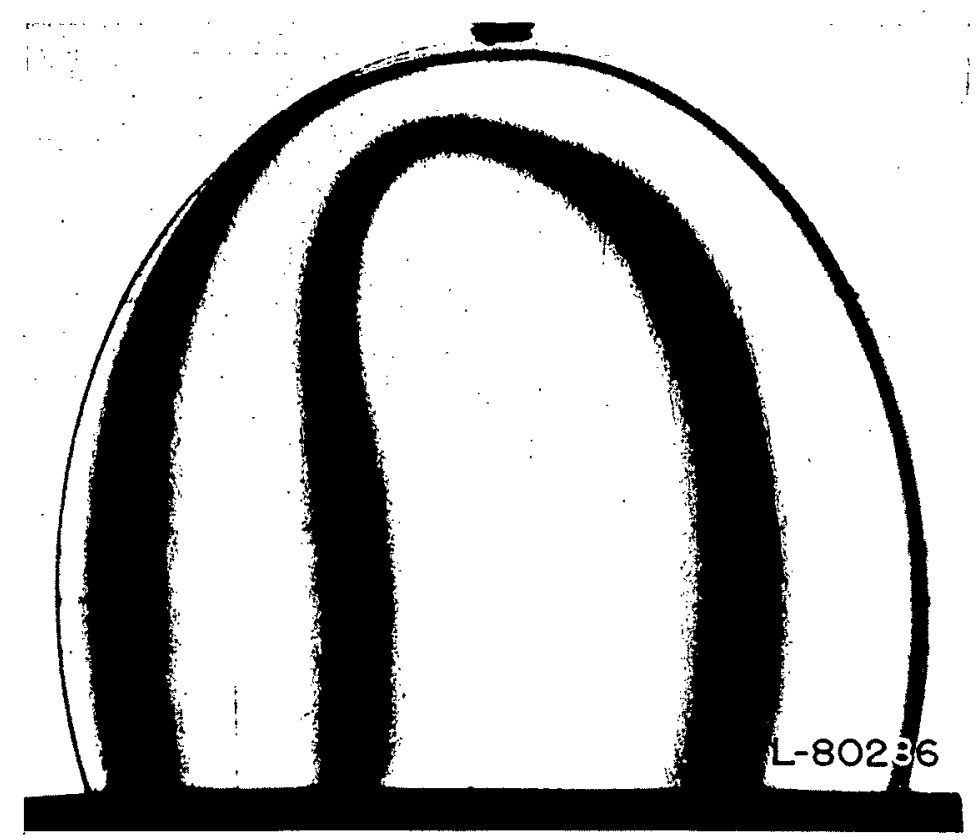

Figure 15.- Stress pattern of slice parallel to meridian for a rotation of $45^{\circ}$ about $Y$-axis.

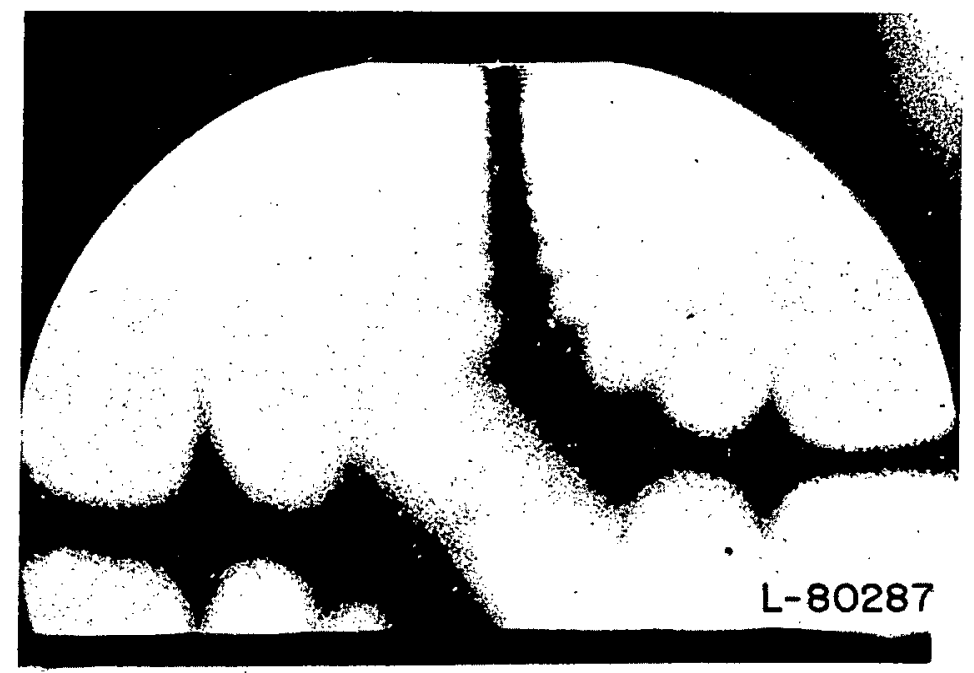

Figure 16.-Typical isoclinic for meridian slice.

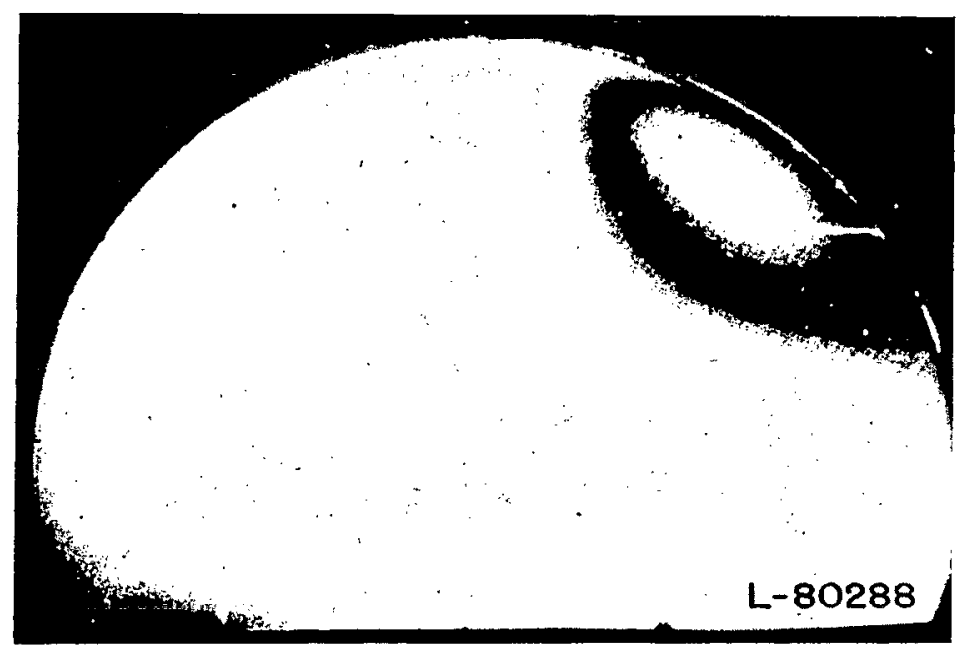

FIGURE 17.- Typical isoclinic for slice parallel to meridian. was used with attention being confined to the particular line of interest. Here the intersections of successive isoclinic lines with the line of interest were obtained at very short intervals, from which the distribution of the isoclinic parameters along the line could be plotted. This method was found to be accurate and considerably less time consuming than the photographic method. White light was used in all isoclinic work.

In plane stress systems the isoclinic parameter at a point on a free boundary is determined by the tangent to the boundary at the point. The isoclinic parameter thus changes from point to point along the boundary in general. This is not necessarily true for isoclinics of secondary principal stresses. In the slice parallel to the meridian the secondary principal stresses at the boundary consist solely of one normal stress $\sigma_{z}$ which is horizontal. The boundary is therefore a zero isoclinic and no other isoclinic may intersect the boundary at any point. The higher order isoclinics therefore all lie within the boundary forming closed loops in this case, as shown in figure 17 .

Fringe value. - The fringe value of the material was obtained from a small cylinder about $1 / 2$ inch in diameter and $1 \frac{1}{2}$ inches long. This was loaded in compression in the special loading jig used for the sphere and subjected to the same thermal cycle as the sphere. A portion of the cylinder was machined away to leave a $V$ shape as shown in figure 18 . The resulting stress pattern was then photographed (fig. 19). The $V$ shape was used to make clearly visible the fringe of zero order occurring at the sharp edge of the wedge. In the cylinder itself the first few fringes crowd together near the boundary of the cylinder and it is practically impossible to identify the zero fringe. From the stress pattern in figure 19 it was a simple matter to plot fringe order against position, which for the wedge described is a straight line (fig. 20).

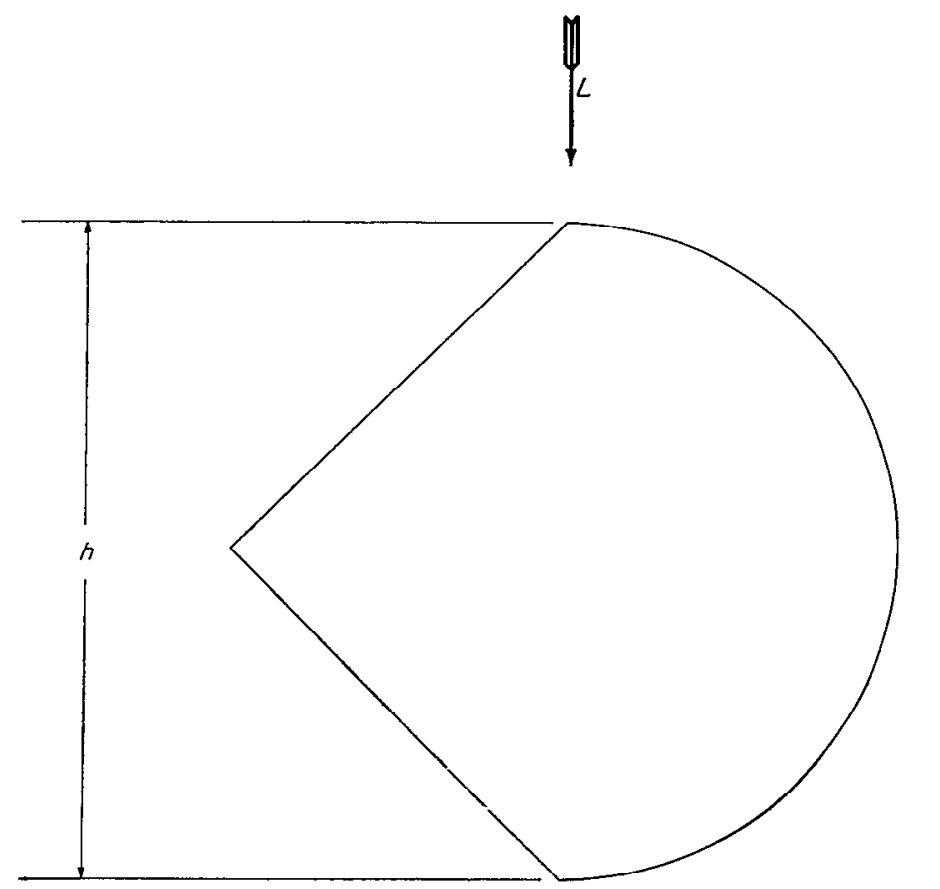

FIGURE 18.-Cross section of calibration member after machining of wedge. 


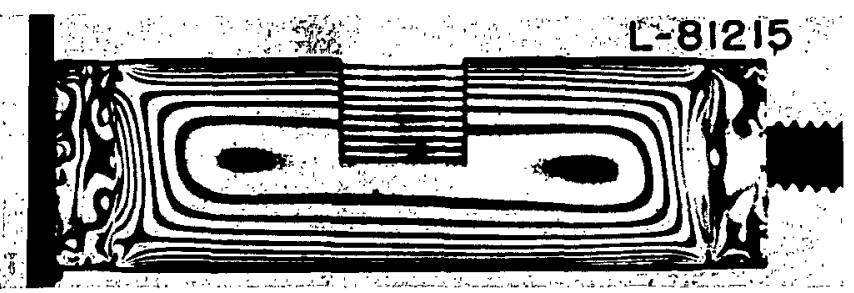

FIGURE 19.- Stress pattern of calibration member.

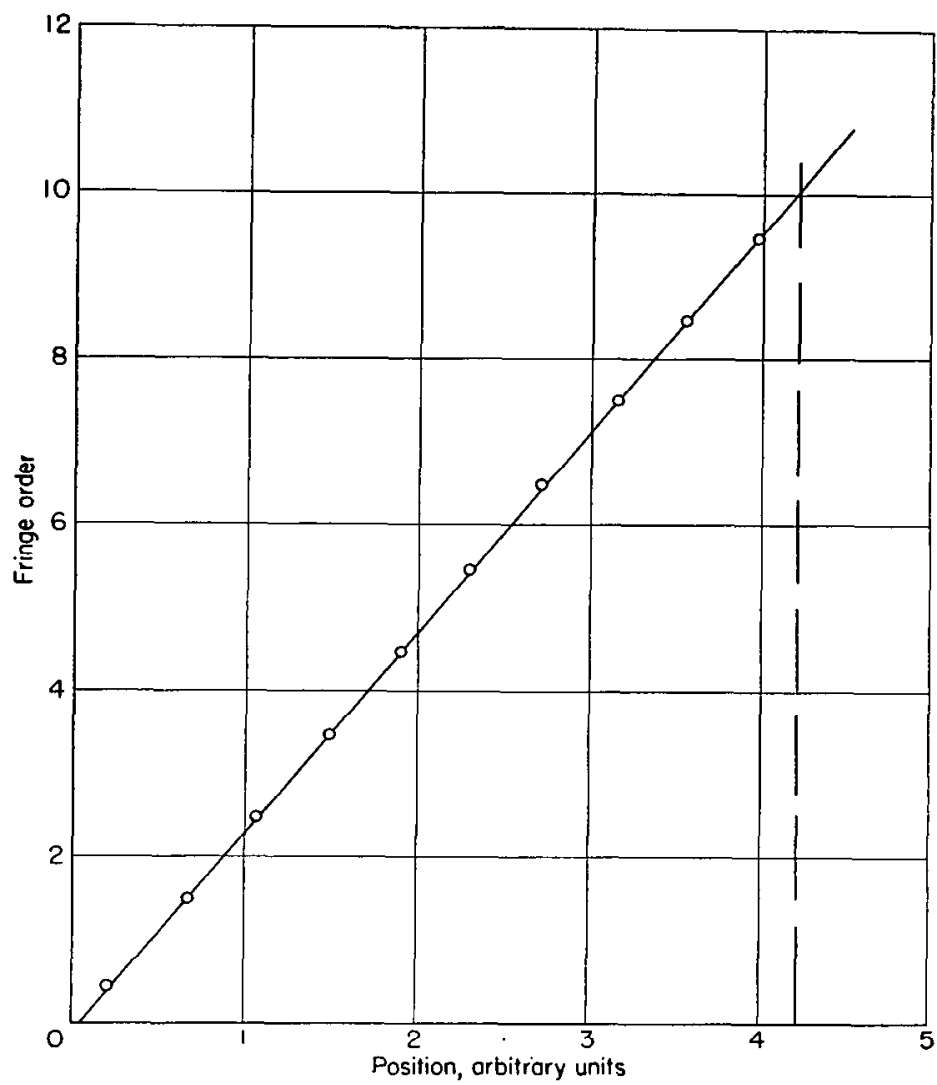

Figure 20.-Fringe order for calibration member as a function of distance from edge of wedge.

In this way the fringe order at the point where the plane faces of the $V$ intersect the curved boundary of the cylinder could be accurately determined. At the same point the thickness $h$ could also be measured accurately. With the measured fringe order and thickness the fringe value $2 f$ of the material was found to be 3.0 psi per fringe, per inch compression.

\section{RESULTS}

Interior stresses.-The stress distribution was obtained along six lines passing through the interior of the sphere. The lines are indicated in figure 21 by the letters $A-A, B-B$, $\mathrm{C}-\mathrm{C}, \mathrm{D}-\mathrm{D}, \mathrm{E}-\mathrm{E}$, and $\mathrm{F}-\mathrm{F}$. Thus the six lines are defined as follows:

A-A intersection of meridian slice with equatorial slice

$\mathrm{B}-\mathrm{B}$ intersection of meridian slice with slice parallel to equator

C-C intersection of slice parallel to equator with slice parallel to meridian

D-D load line

$\mathrm{E}-\mathrm{E}$ intersection of equatorial slice with slice parallel to meridian
F-F .. intersection of slice parallel to the meridian slice with a meridian plane which is perpendicular to it

In this problem advantage was taken of the symmetry of the sphere to eliminate the need for two models as discussed in the theoretical part of the report. In particular because of the rotational symmetry of the stresses one meridian slice could be taken to represent all meridian slices.

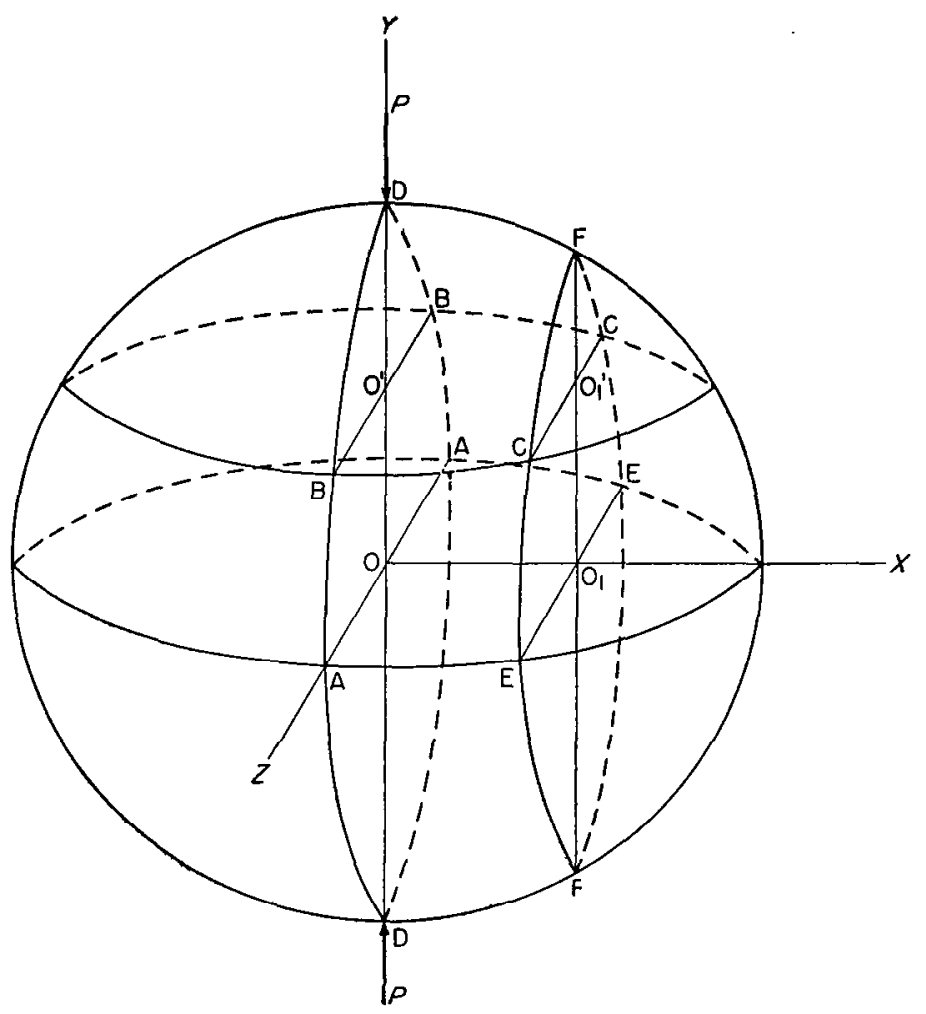

Figure 21.- Lines in sphere along which stress distributions wero determined.

Typical calculation. In order to make clear the application of the method the complete calculations for line $\mathrm{C}-\mathrm{C}$ will now be given. The cvaluation of the stresses along this line requires all the generality which would be encountered in a body devoid of symmetry. The basic data for the determination of the stresses on this line are obtained from the stress patterns and isoclinies at normal incidence of the two slices defining the line $\mathrm{C}-\mathrm{C}$ and from the stress pattern and isoclinics of one of the slices at oblique incidence with rotation about an axis perpendicular to $\mathrm{C}-\mathrm{C}$ and lying in the plane of the plate.

Because of the symmetry of the stresses along $\mathrm{C}-\mathrm{C}$ it is necessary only to deal with half the length of the line. This half length was divided into 10 equal subdivisions. The two necessary auxiliary lines were drawn parallel to it in each of the two orthogonal planes and spaced the length of one subdivision apart.

The first step is to obtain the distribution of the shearing stresses along line $\mathrm{C}-\mathrm{C}$ and along the four auxiliary lines. This requires the determination of the distribution of the secondary principal stress differences and of the isoclinics along these lines. Figure 22 shows the curves of $n^{\prime \prime \prime}$ and $\phi^{\prime \prime \prime}$ for the slice parallel to the meridian, and figure 23 


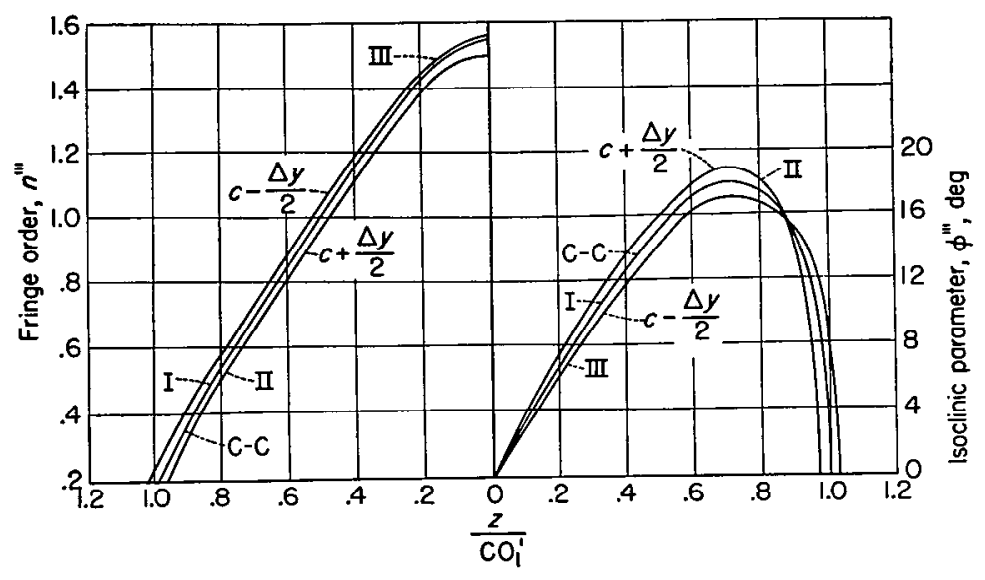

FIgURE 22.-Distribution of fringe order $n^{\prime \prime}$ and isoclinic parameter $\phi^{\prime \prime \prime}$ for line $\mathrm{C}-\mathrm{C}$ and two auxiliary lines in slice parallel to meridian. In curves II and III the letter $c$ denotes the $\mathrm{Y}$-coordinate of line $\mathrm{C}-\mathrm{C}$.

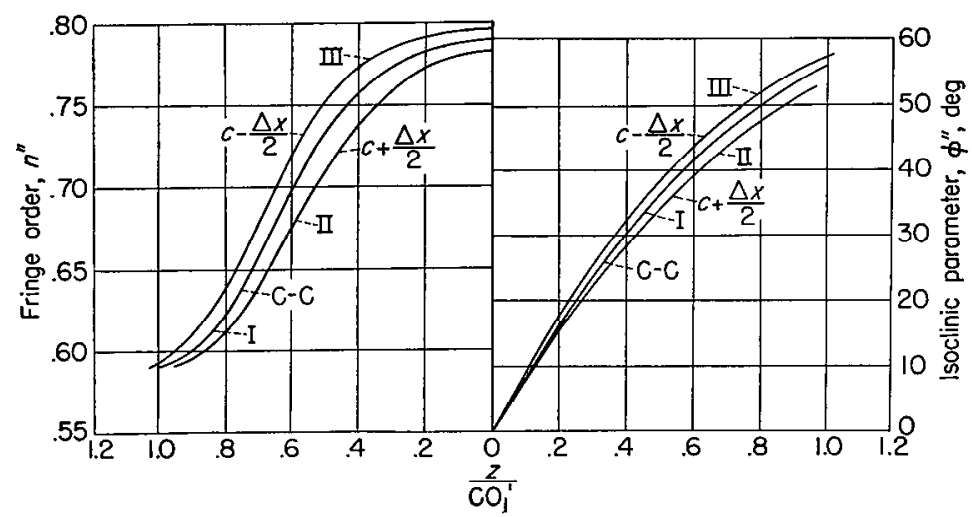

Firtire 23.-Distribution of fringe order $n^{\prime \prime}$ and isoclinic parameter $\phi^{\prime \prime}$ for line C-C and two auxiliary lines in slice parallel to equator. In curves II and III the letter $c$ denotes the $Y$-coordinate of line $\mathrm{C}-\mathrm{C}$.

shows $n^{\prime \prime}$ and $\phi^{\prime \prime}$ for the slice parallel to the equator. With these data the required shearing stresses are computed at each division point of $\mathrm{C}-\mathrm{C}$. Thus, following equations (12) and expressing the stresses in terms of fringes,

$$
\begin{aligned}
& n_{y z}=\frac{1}{2} n^{\prime \prime \prime} \sin 2 \phi^{\prime \prime \prime} \\
& n_{x z}=\frac{1}{2} n^{\prime \prime} \sin 2 \phi^{\prime \prime}
\end{aligned}
$$

It will be noted that for positive values of $z$ the shear system $n_{y z}$ is positive and $n_{x z}$ is negative.

As noted in the theoretical part of the report the integration requires the use of the difference between the shearing stresses at the center of each subdivision. These differences are obtained from the curves representing the distribution of the shearing stresses just found. Figure 24 shows the curves of the shear differences for the two slices.

The next step is to obtain the value of the normal stress $n_{z}$ at each division point by an integration of one of the dif-

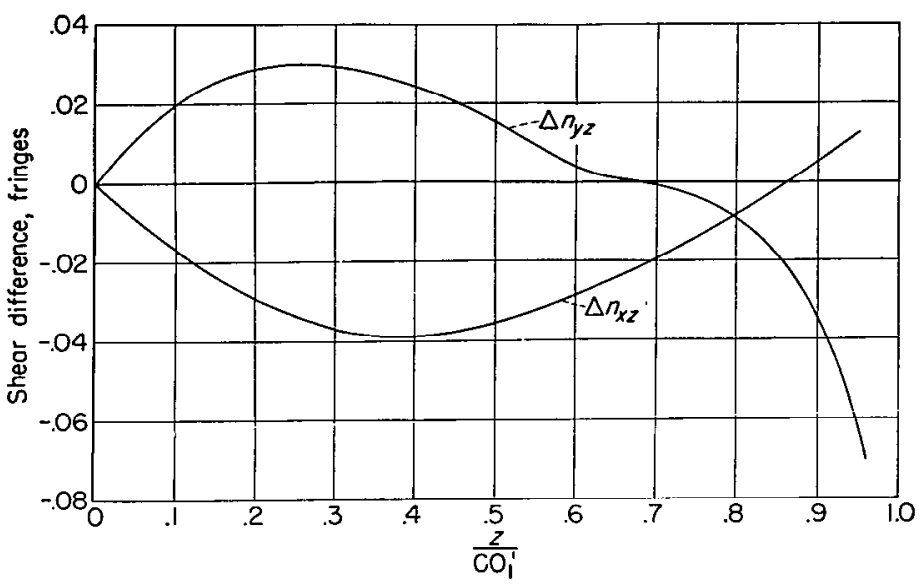

FIgURE 24.-Distribution of shear differences $\Delta n_{y z}$ and $\Delta n_{x z}$ for line $C-C$.

ferential equations of equilibrium. The integration is carried out by approximation using summations to replace the integrals. The appropriate equation for line $\mathrm{C}-\mathrm{C}$ is similar to equation (11a), that is,

$$
\left(n_{z}\right)_{j}=\left(n_{z}\right)_{c}-\sum_{c}^{j} \Delta n_{y z} \frac{\Delta z}{\Delta y}-\sum_{c}^{j} \Delta n_{x z} \frac{\Delta z}{\Delta x}
$$

Choosing $\Delta x=\Delta y=\Delta z$ the ratios of these quantities are unity. The signs of the ratios depend on the choice of axes and the direction of integration. The integration begins at the boundary and proceeds inward. Consequently $\Delta z$ is negative. The shear differences have been formed in such a way that $\Delta y$ is positive and $\Delta x$ negative. The final form of the equation is therefore

$$
\left(n_{z}\right)_{j}=\left(n_{z}\right)_{c}+\sum_{c}^{j} \Delta n_{y z}-\sum_{c}^{j} \Delta n_{x z}
$$

The signs of the shear differences are as shown by the curves.

In order to start the integration the value of $\left(n_{z}\right)_{c}$ is required. This must be determined from the boundary conditions and boundary fringe orders. From the fact that the boundary is unloaded it is evident that the principal stress normal to the boundary is zero. Inspection of the meridian slice shows that, excepting the loaded regions, the boundary stresses in the meridian section are also zero. The fringe order at the boundary of the slice parallel to the equator is 0.58 fringe tension, and the direction of this stress makes an angle of $55.6^{\circ}$ with line C-C. The boundary value of $n_{z}$ is thus found from the equations of stress transformation as follows:

$$
\left(n_{z}\right)_{c}=0.58 \cos ^{2} 55.60=0.185
$$

The expression for $\left(n_{z}\right)_{j}$ therefore takes the form

$$
\left(n_{z}\right)_{j}=0.185+\sum_{c}^{j} \Delta n_{y z}-\sum_{c}^{j} \Delta n_{x z}
$$

The integration is easily carried out in tabular form as shown in table I. 
Once $n_{z}$ has been found the values of $n_{x}$ and $n_{y}$ are found from expressions similar to equation (13c), that is,

$$
\begin{aligned}
& n_{x}=n_{z}-n^{\prime \prime} \cos 2 \phi^{\prime \prime} \\
& n_{y}=n_{z}-n^{\prime \prime \prime} \cos 2 \phi^{\prime \prime \prime}
\end{aligned}
$$

This computation is shown in table II.

The last step is to determine the remaining shearing stress system $n_{x y}$. 'This was obtained in this case from oblique incidence on the slice parallel to the meridian with rotation through $45^{\circ}$ about the $Y$-axis. Figure 25 shows the fringe order and isoclinic distributions along $\mathrm{C}-\mathrm{C}$ for this case. With these data and the known values of $n_{y z}$ previously determined the required shearing stress component is found from an expression similar to equation (15c). Thus

$$
n_{x y}=\frac{1}{2} n_{\theta y} \sin 2 \phi_{\theta y}-n_{y z}
$$

The results of this computation are shown in table III. This completes the solution for all six stress components along line $\mathrm{C}-\mathrm{C}$. In order to determine the stress components in pounds per square inch it is necessary only to multiply the stresses in fringes by the proper fringe value of the slice.

Using methods similar to those just explained the stress components for all six lines have been delermined. With the exception of line D-D integration began at the boundary and proceeded inward. For line $\mathrm{D}-\mathrm{D}$ the starting point was

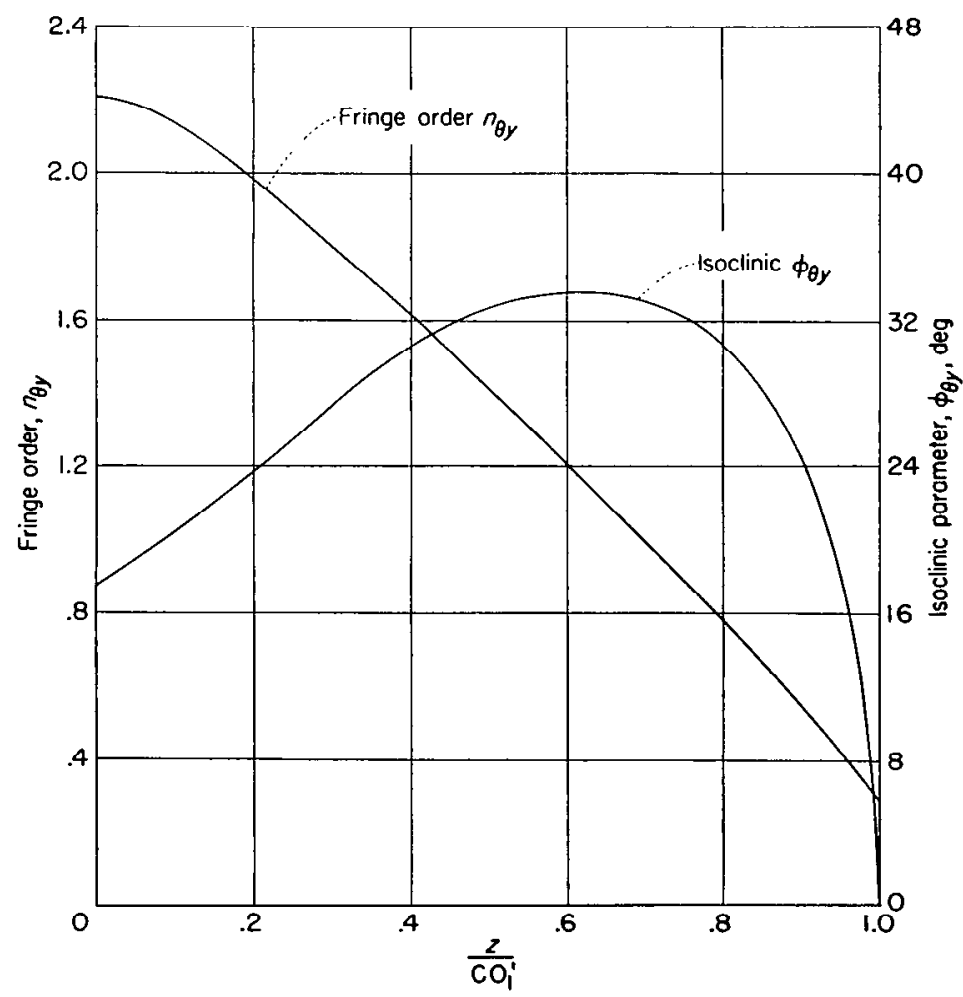

FIGURE 25.-Distribution of $n_{\theta_{y}}$ and $\phi_{\theta_{y}}$ along line $\mathrm{C}-\mathrm{C}$ for a $45^{\circ}$ rotation of slice parallel to the meridian about the $Y$-axis. taken as the center of the sphere and integration proceeded upward. The starting value of $n_{y}$ for this line was taken to be that obtained from line $\mathrm{A}-\mathrm{A}$. The results of these computations are shown in figures 26 to 32 . At the center of the sphere the stress components were found to be $\sigma_{y}=-2.59 P / A$ and $\sigma_{x}=\sigma_{z}=0.45 P / A$. These values may be compared with the stresses at the center of a disk under diametral compression which are $\sigma_{y}=-1.91 P / A$ and $\sigma_{x}=0.64 P / A$.

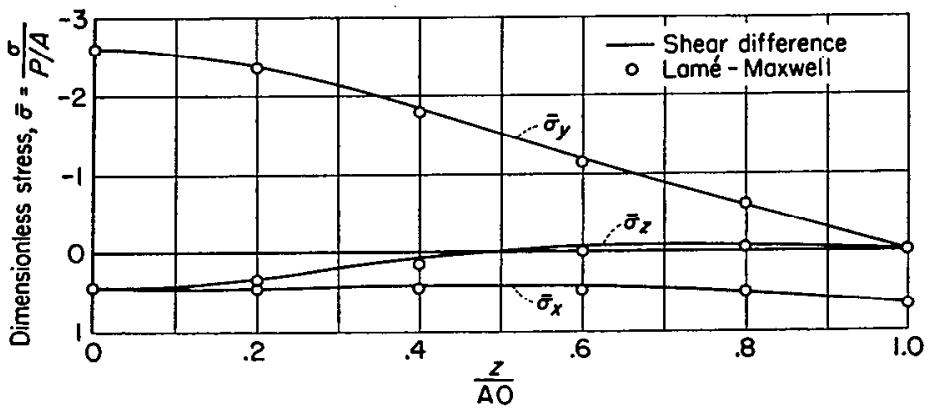

Figure 26.-Distribution of normal stresses along line A-A.

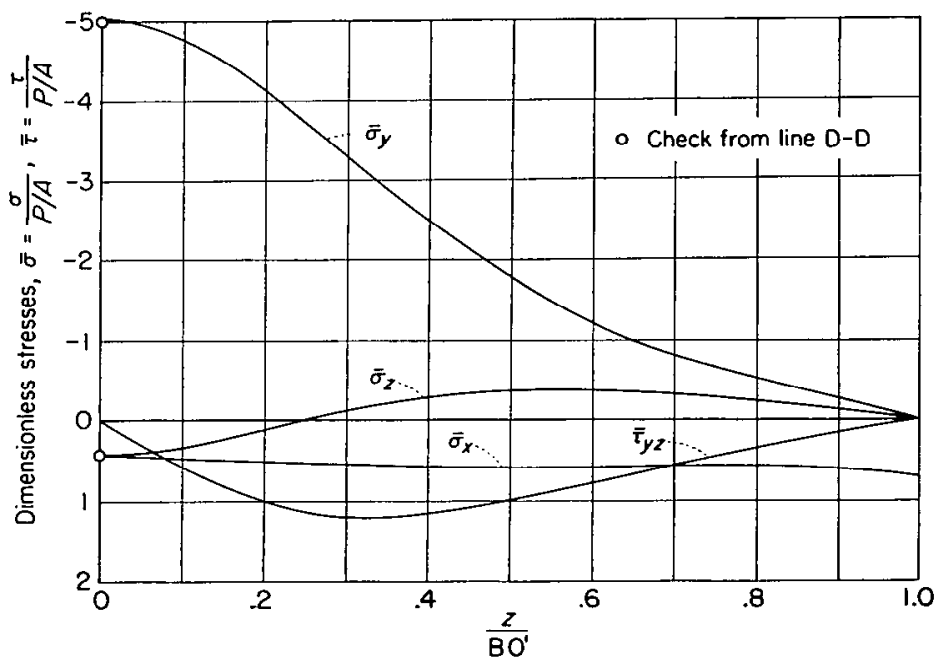

Figure 27.-Distribution of stresses along line $\mathrm{B}-\mathrm{B}$.

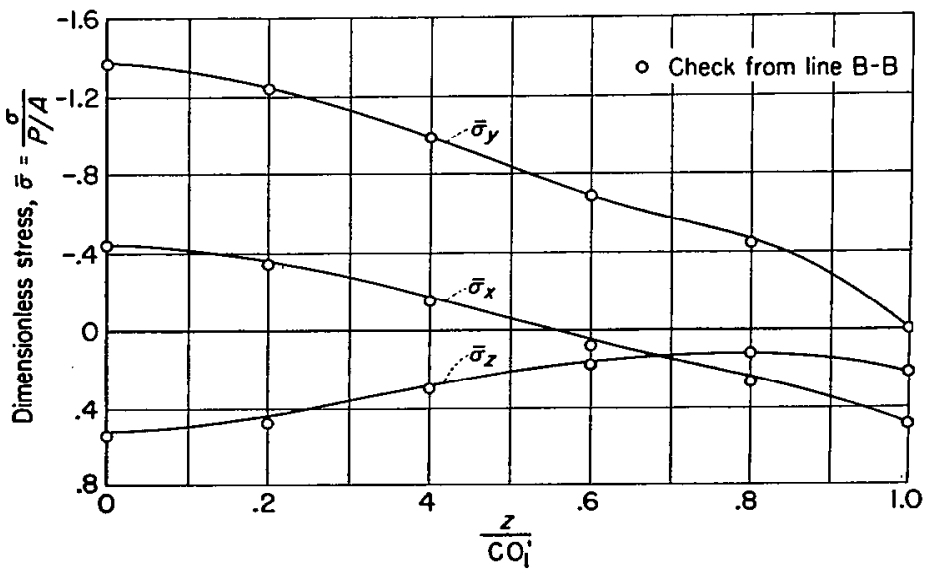

Figure 28.-Distribution of normal stresses along line $\mathrm{C}-\mathrm{C}$. 


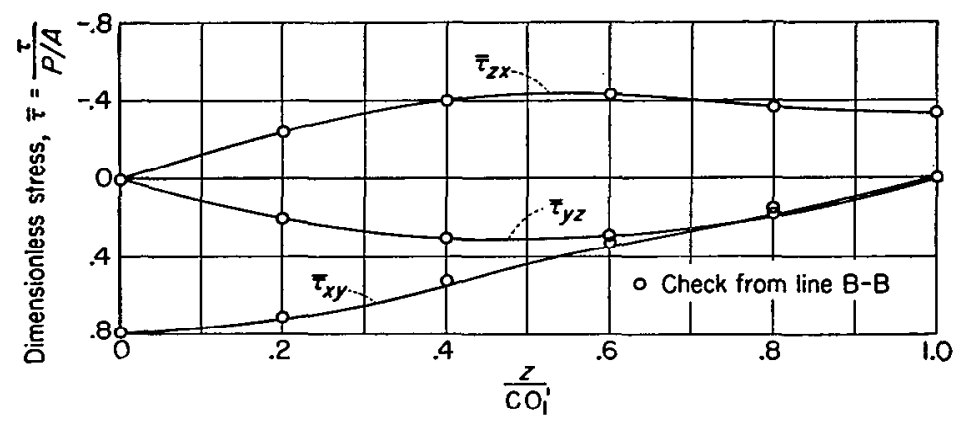

Figure 29.-Distribution of shearing stresses along line $\mathrm{C}-\mathrm{C}$.

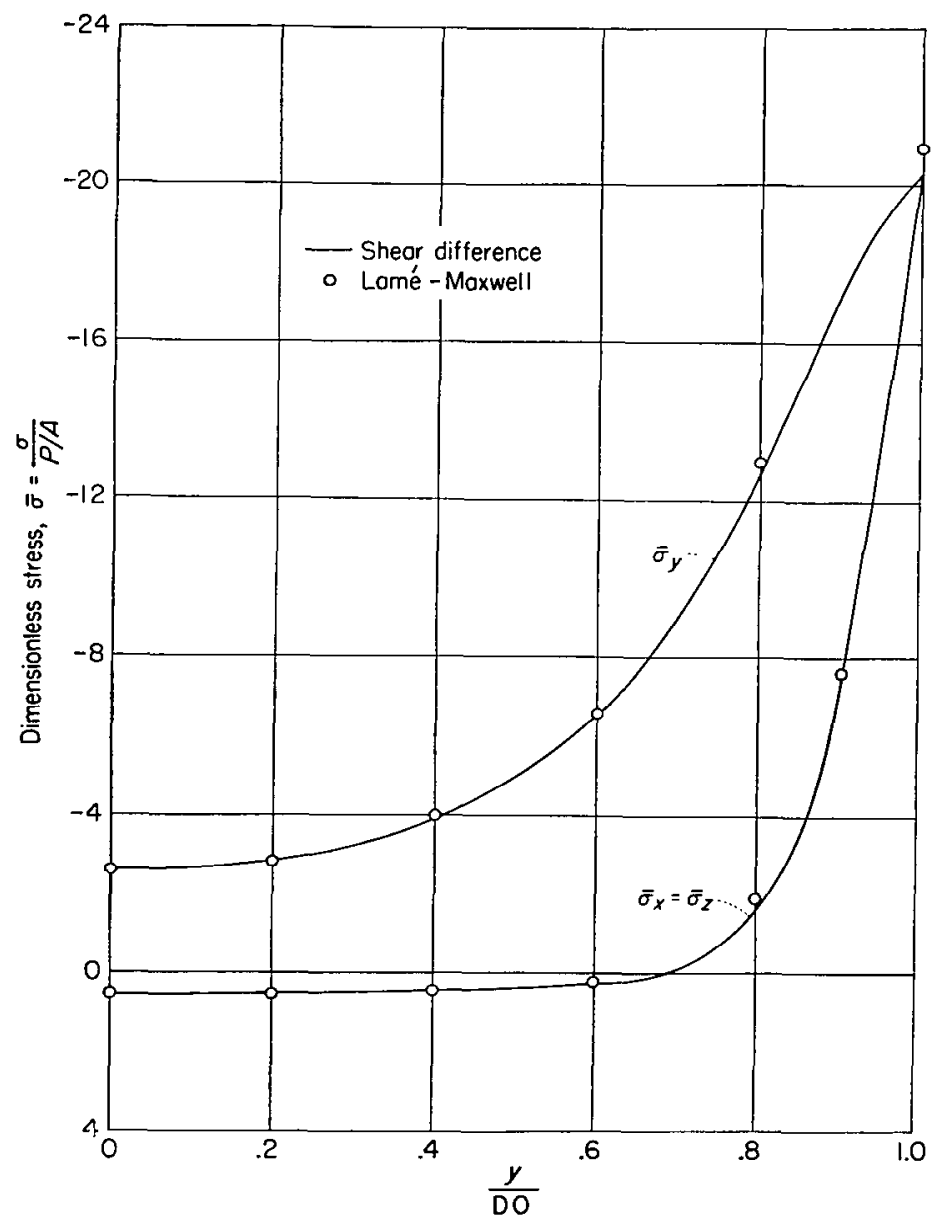

Figure 30.-Distribution of stresses along line D-D.

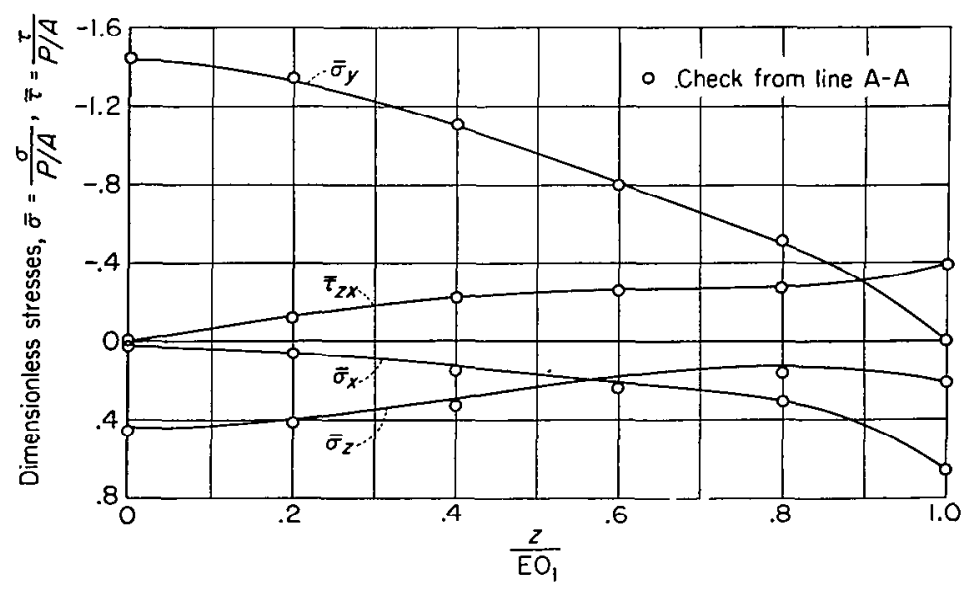

FIGURE 31.-Distribution of stresses along line L-E.

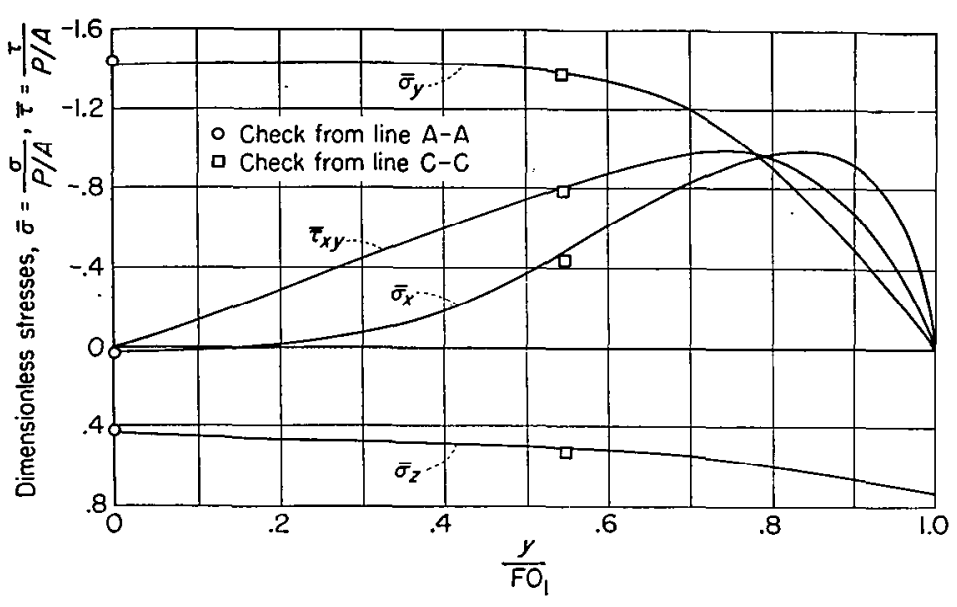

FIGURE 32.-Distribution of stresses along line F-F.

Contact stresses at load points. - As noted previously the loads on the sphere produced considerable local deformation which resulted in flattened areas at the poles. Upon observation of the meridian slice it was found that fringes and isoclinics were unusually clear right to the loaded boundary. It was therefore possible to continue the integration all the way to the loaded boundary along lines normal to the areas of contact and thereby to obtain approximations to the contact stresses. The stress components at the ends of line $\mathrm{D}-\mathrm{D}$ represent the contact stresses at the poles, that is, at the center's of the loaded areas. In order to determine, at least roughly, the actual distribution of the contact stresses over the loaded areas two additional slices normal to the loaded zones were cut from the remaining material of the sphere. The intersections of these slices with the meridian slice then define two lines parallel to line $D-D$ which extend from line B-B to the loaded boundary. Starting values were taken from the stress distribution on line B-B previously obtained, and integration proceeded to the loaded boundary in the usual fashion. In this way the contact stresses at two points at different distances from the center were obtained. With these three points the distribution of the normal stresses on the contact surface could be pretty well determined. The shearing stresses acting on the surface of contact were found from the values of $n^{\prime}$ and the isoclinics $\phi^{\prime}$ in a meridian section in the region of contact. The results are shown in figure 33, the directions of the shearing stresses being from the poles outward.

Checks on accuracy.-Two types of checks are available in this problem, static checks and checks between stresses on different lines. Static checks were made from the stresses on lines $\mathrm{A}-\mathrm{A}$ and $\mathrm{B}-\mathrm{B}$ and from those acting on a diameter in the surfaces of contact. Since these stresses are rotation. ally symmetrical the resultant force acting on the equatorial plane and on the plane containing line $\mathrm{B}-\mathrm{B}$ parallel to the equator as well as on the plane of contact can be determined by integration. From the stresses on line $\mathrm{A}-\mathrm{A}$ the resultant load on the equatorial plane was computed as 176 pounds, which is 2.3 percent higher than the applied load of 172 pounds. The stresses on line $\mathrm{B}-\mathrm{B}$ gave a resultant of 168 pounds which is 2.3 percent low. Lastly the resultant of the normal stresses on the surface of contact was found to be 170 pounds, or 1.2 percent low. 


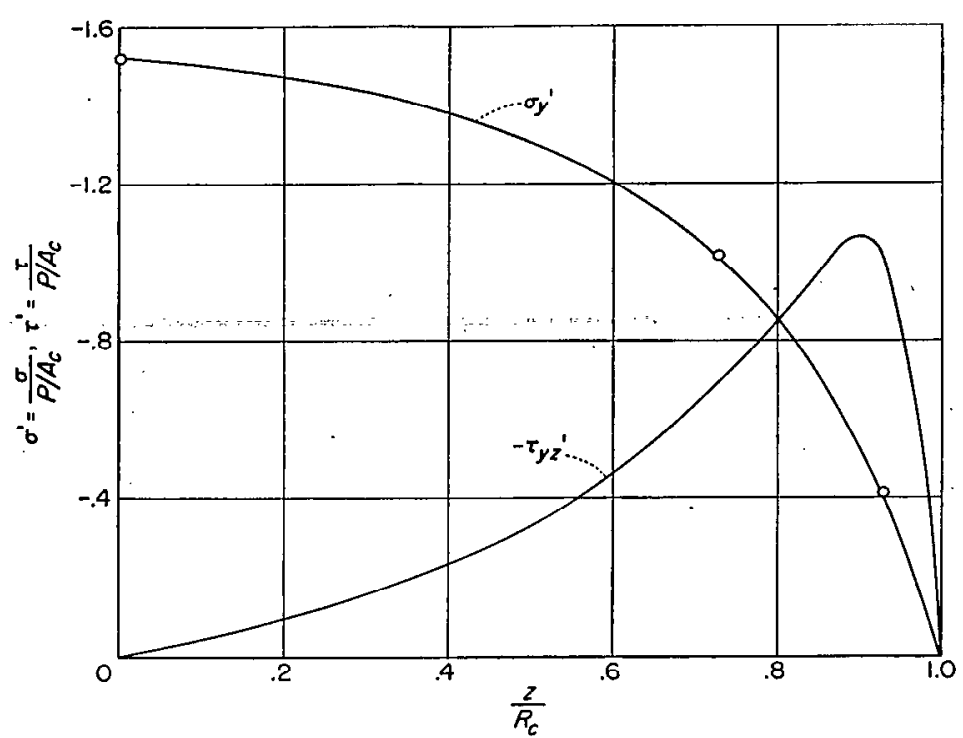

FIGURE 33.-Distribution of stresses on surfaces of contact.

Points $\mathrm{O}^{\prime}$ and $\mathrm{O}_{1}{ }^{\prime}$ (fig. 21) are common points on different lines. The stresses at these points can be determined from each line and the results compared. The stresses at, $\mathrm{O}^{\prime}$ were found by integrating along line $\mathrm{B}-\mathrm{B}$ and also by integration along the path $\mathrm{AOO}^{\prime}$. From line $\mathrm{B}-\mathrm{B}$ the stresses were found to be $n_{y}=-4.08$ and $n_{x}=n_{z}=0.40$. From the path $\mathrm{AOO}^{\prime}$ they were found to be $n_{y}=-4.06$ and $n_{x}=n_{z}=0.42$. At $\mathrm{O}_{1}{ }^{\prime}$ the stresses are found from lines $\mathrm{C}-\mathrm{C}$ and $\mathrm{F}-\mathrm{F}$. From line $\mathrm{C}-\mathrm{C}$ the stresses were computed as $n_{1}=-1.12$, $n_{x}=-0.36, n_{z}=0.43$, and $n_{x y}=0.62$. From line $\mathbf{F}-\mathrm{F}$ they were $n_{y}=-1.14, n_{x}=-0.39, n_{z}=0.40$, and $n_{x y}=0.66$. The agreement in these values is seen to be quite good.

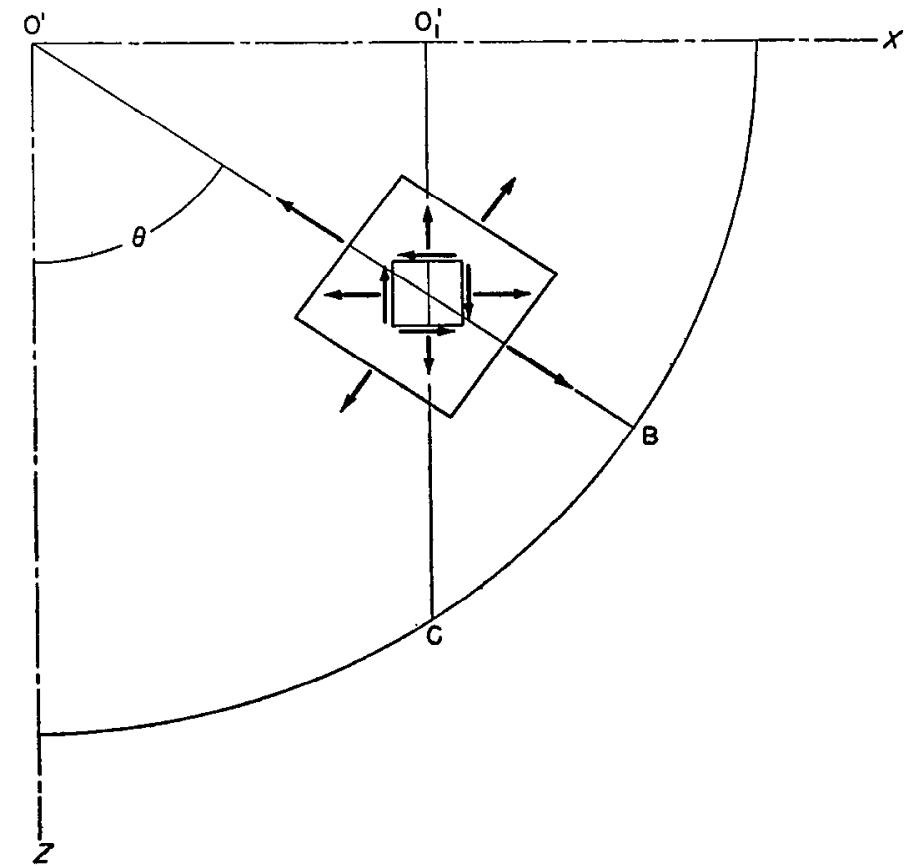

FiquRE 34.-Sketch relating stress components at a point on line $\mathrm{P}-\mathrm{B}$ to those on line $\mathrm{C}-\mathrm{C}$.
It is also possible to compute the stresses on lines $\mathrm{C}-\mathrm{C}$ and $\mathrm{E}-\mathrm{E}$ from the stresses on lines $\mathrm{A}-\mathrm{A}$ and $\mathrm{B}-\mathrm{B}$. Figure 34 shows the rectangular stress components on lines $\mathrm{C}-\mathrm{C}$ and $\mathrm{B}-\mathrm{B}$. The necessary equations for transformation are similar to the familiar equations for inclined planes in plane stress systems, that is,

$$
\begin{gathered}
\sigma_{\theta}=\frac{\sigma_{x}+\sigma_{y}}{2}+\frac{\sigma_{x}-\sigma_{y}}{2} \cos 2 \theta+\tau_{x y} \sin 2 \theta \\
\tau_{\theta}=\frac{\sigma_{x}-\sigma_{y}}{2} \sin 2 \theta-\tau_{x y} \cos 2 \theta
\end{gathered}
$$

The stresses computed by transformation were compared with the stresses independently determined on lines $\mathrm{C}-\mathrm{C}$ and $\mathrm{E}-\mathrm{E}$ by integration. The comparative values are shown in figures 28, 29, and 31. The general agreement is seen to be excellent.

Check by the Lame-Maxwell equations.-Lines A-A and D-D are lines of symmetry for the sphere. For these special lines the stresses can be computed by the method outlined by Jessop (reference 18) using the extension of the LaméMaxwell equations to three dimensions. This computation has been carried out using fringe orders from the meridian and equatorial slices and the $5^{\circ}$ isoclinic from the meridian slice. The comparative values are given in figure 26 for line $\mathrm{A}-\mathrm{A}$ and in figure 30 for line $\mathrm{D}-\mathrm{D}$. Inspection of the figures shows that in both cases the agreement is close.

\section{ANALYSIS AND DISCUSSION}

The primary objective of the project under discussion was to develop a general method for solving three-dimensional problems photoelastically. In the theoretical part of this report such a method is described. The experimental work shows that the proposed method is practical.

It is too early to draw broad conclusions regarding the general accuracy of the new method. IIowever, the excellence of the static checks and the consistency of the results, as shown by the close cross checks between the results from the various lines, seem to indicate possibilities of high accuracy. Unfortunately there is as yet no theoretical solution available for this particular problem to furnisb conclusive checks and a measure of the errors. ${ }^{2}$ Nevertheless there is a reasonable degree of certainty that the major stresses are frce from significant error.

It must be pointed out that the stresses as found here represent the solution for a material for which Poisson's ratio is 0.48 , whereas most structural materials have Poisson's ratios of about 0.3 . This is an inherent limitation of threedimensional photoelasticity. However, as noted previously, the theoretical solutions available to date indicate that Poisson's ratio has only a small influence on the major stresses although the effect on the minor stresses may be pronounced (references 19 and 20).

Although no theoretical solution is available for the sphere Hertz's solution can be used to check the contact stresses 
determined photoelastically. According to Hertz's solution the contact pressure is representable by the ordinates to a hemisphere erected on the contact surface. Further the Hertz theory predicts that the maximum contact pressure should be $1.5 P / A_{c}$. Reference to figure 33 shows that the experimentally determined value of the maximum pressure is $1.53 P / A_{c}$, which is 2 percent high. When it is considered that the path of integration used in determining the maximum. pressure led along an equatorial radius to the center and thence up the load axis to the surface this is indeed a remarkable check. The general distribution of the pressures is also seen to be substantially correct. The proposed method would therefore seem to hold considerable promise for the determination of contact stresses.

According to the Hertz theory the two principal stresses in the plane of the contact surface at the pole, $\sigma_{x}$ and $\sigma_{z}$, should each equal $\frac{1+2 \nu}{2} \sigma_{y}$. For Poisson's ratio of $1 / 2$ this reduces to $\sigma_{x}=\sigma_{z}=\sigma_{y}$ which indicates that an isotropic point exists at the pole, and therefore the shearing stress is zero at this point. This is borne out by the photoelastic results.

Along the circular boundary of the surface of contact the stress consists of a pure shear of the amount $\left(\frac{1-2 \nu}{3}\right) \frac{P}{A_{c}}$ according to the Hertz theory. If Poisson's ratio is $1 / 2$ this expression vanishes. Hence the normal and shearing stresses at the boundary should be zero. The photoelastic results are seen to give this value.

The problem treated in this report has complete rotational symmetry which simplifies the experimental technique by eliminating the use of two models. No problem has as yet been solved which requires two models. The use of two models will no doubt introduce complications, but no insurmountable difficulties are anticipated. However, further work must be done to demonstrate the effectiveness of the proposed method with two models.

There remains also the possibility of using sub slices from the main slice as discussed in the theoretical part. 'The model used in this investigation was not large enough to make this procedure feasible although some attempts were made. This possibility also needs to be further explored.

It will perhaps also be desirable to repeat the solution of the sphere with smaller loads in order to reduce the relatively large local deformations.

\section{SUMMARY OF RESULTS}

The results from this investigation to develop a general method for three-dimensional photoelastic stress analysis may be summarized as follows:

1. The method of strain measurement after annealing cannot be used with the materials now available in this country.

2. A general photoelastic method for obtaining six stress components at any point of an unsymmetrical body arbitrarily loaded has been developed. This method does not depend on Poisson's ratio, although the results reflect the physical constants of the model.
3. The new method is applicable in the plastic range of the model.

4. The method shows possibilities for the determination of contact stresses.

5. The stresses existing in a sphere subjected to diametral compression have been determined with considerable accuracy.

6. At the center of the sphere the stress components were found to be $\sigma_{y}=-2.59 P / A$ and $\sigma_{x}=\sigma_{z}=0.45 P / A$, where $P$ is the load on the sphere and $A$ is the arca of the equatorial plane of the sphere. These values may be compared with the stresses at the center of a disk under diametral compression which are $\sigma_{y}=-1.91 P / A$ and $\sigma_{x}=0.64 P / A$.

7. Further work is needed to determine the full potentialities of the method when two models are used. Further work is also needed to determine the practicability of sub slices.

Illinois Institute of Thomology,

Chicago 16, Ill., September 15, 1951.

\section{REFERENCES}

1. Prigorovsky, N. I., and Preiss, A. K.: Issledovanye Napryazionnavo Sostoyaniya $\mathrm{Na}$ Prozrachnykh Obyemnykh Modelyakh v Putchke Parallelnykh Luchey Polarizovanavo Svyeta (An Investigation of the State of Stress in Transparent ThreeDimensional Models in Parallel Beams of Polarized Iight). Izvestiâ Akad. Nauk S. S. S. R., Otdelenic Tekh. Nauk, no. 5, May 1949, pp. 686-700. (See also M. M. Frocht's review of this paper in Appl. Mech. Rev., vol. 3, no. 2, Feb. 1950, p. 38.)

2. Oppel, G.: Polarisationsoptische Untersuchung räumlicher Spannungs- und Dehnungszustände. Forsch. Geb. Ing.-Wes., Bd. 7, Nr. 5, Sept./Oct. 1936, pp. 240-2+8.

3. Frocht, Max Mark: Photoelasticity. Vol. II. John Wiley \& Sons, Inc., 1948.

4. Hetényi, M.: The Fundamentals of Three-Dimensional Photoelasticity. Jour. Appl. Mech., vol. 5, no. 4, Dec. 1938, pp. A-149A-155.

5. Kuske, A.: Das Kunstharz Phenolformaldehyd in der Spannungsoptik. Forsch. Geb. Ing.-Wes., Bd. 9, Nr. 3, May/June 1938, pp. 139-149.

6. Drucker, Daniel C., and Mindlin, Raymond D.: Stress Analysis by Three-Dimensional Photoelastic Methods. Jour. Appl. Phys., vol. 11, no. 11, Nov. 1940, pp. 724-732.

7. Drucker, D. C.: Photoelastic Separation of Principal Stresses by Oblique Incidence. Jour. Appl. Mech., vol. 10, no. 3, Sept. 1943, pp. A-156-A-160. (See also discussion by M. M. Frocht, Jour. Appl. Mech., vol. 11, no. 2, June 1944, pp. A-125-A-126.)

8. Frocht, Max Mark: Photoelasticity. Vol. I. John Wiley \& Sons, Inc., 1941.

9. Weller. R.: A New Method for Photoelasticity in Three Dimensions. Jour. Appl. Phys., vol. 10, no. 1, April 1939, p. 266.

10. Weller, R., and Bussey, J. K.: Photoelastic Analysis of ThreeDimensional Stress Systems Using Scattered Light. NACA TN 737, 1939.

11. Menges, Hermann Josef: Die experimentelle Ermittlung räumlicher Spannungszustände an durchsichtigen Modellen mit Hilfe des Tyndalleffektes. Z. a. M. M., Bd. 20, Heft 4, Aug. 1940, pp. $210-217$.

12. Hiltscher, R.: Polarisationsoptische Untersuchung des räumlichen Spannungszustandes im konvergenten Licht. Forsch. Geb. Ing.-Wes., Bd. 9, Nr. 2, March/April 1938, pp. 91-103.

13. Kuske, A.: Vereinfachte Auswerteverfahren räumlicher spannungsoptischer Versuchc. Z. V. D. I., Bd. 86, Nr. 35/36, Sept. 5, 1942 , pp. 541-544. 
14. Leven, M. M., and Frocht, M. M.: Photoelastic Determination of Stresses on the Surface of Poppet Valves. Proc. First U. S. Nat. Cong. Appl. Mech. (June 1951, Chicago, Ill.), A. S. M. E., 1952, pp. $317-324$.

15. Leven, M. M.: Stresses in Keyways by Photoelastic Methods and Comparison with Numerical Solution. Proc. Soc. Exp. Stress Analysis, vol. VII, no. 2, 1949, pp. 141-154.

16. Hetényi, M.: A Photoelastic Study of Bolt and Nut Fastenings. Jour. Appl. Mech., vol. 10, no. 2, June 1943, pp. A-93-A-100.

17. Frócht; Max M:: "Studies in Three-Dimensional PhotoelasticityTorsional Stresses by Oblique Incidence. Jour. Appl. Mech., vol. 11, no. 4, Dec. 1944, pp. A-229-A-234.

18. Jessop, H. T.: The Determination of the Separate Stresses in Three-Dimensional Stress Investigations by the Frozen Stress Method. Jour. Sci. Instr., vol. 26, no. 1, Jan. 1949, pp. 27-31.

19. Sternberg, E., and Sadowsky, M. A.: Three-Dimensional Solution for the Stress Concentration around a Circular Hole in a Plate of Arbitrary Thickness. Jour. Appl. Mech., vol. 16, no. 1, March 1949, pp. 27-38.

TABLE I

NUMERICAL INTEGRATION OF DIFFERENTIAL EQUATION (17c) FOR LINE C-C

\begin{tabular}{|c|c|c|c|}
\hline$\frac{z}{\mathrm{CO}_{1^{\prime}}}$ & $\begin{array}{c}\text { Mean } \\
\Delta n_{y_{z}}\end{array}$ & $\underset{\Delta n_{x z}}{\text { Mean }}$ & $n=$ \\
\hline \multirow[t]{2}{*}{0} & & & 0.431 \\
\hline & 0.012 & -0.009 & \\
\hline \multirow[t]{2}{*}{0.1} & & & 0.410 \\
\hline & 0.025 & -0.024 & \\
\hline \multirow[t]{2}{*}{0.2} & & & 0.361 \\
\hline & 0.030 & -0.034 & \\
\hline \multirow[t]{2}{*}{0.3} & & & 0.297 \\
\hline & 0.028 & -0.038 & \\
\hline \multirow[t]{2}{*}{0.4} & & & 0.231 \\
\hline & 0.021 & -0.038 & \\
\hline \multirow[t]{2}{*}{0.5} & & & 0.172 \\
\hline & 0.009 & -0.033 & \\
\hline \multirow[t]{2}{*}{0.6} & & & 0.130 \\
\hline & 0.001 & -0.024 & \\
\hline \multirow[t]{2}{*}{0.7} & & & 0.105 \\
\hline & -0.004 & -0.014 & \\
\hline \multirow[t]{2}{*}{0.8} & & & 0.095 \\
\hline & -0.019 & -0.001 & \\
\hline \multirow[t]{2}{*}{0.9} & & & 0.113 \\
\hline & -0.060 & 0.012 & \\
\hline 1.0 & & & 0. 185 \\
\hline
\end{tabular}

20. Sadowsky, M. A., and Sternberg, E.: Stress Concentration around a Triaxial Ellipsoidal Cavity. Jour. Appl. Mech., vol. 16, no. 2, June 1949, pp. 149-157.

21. Sternberg, E., and Rosenthal, F.: The Elastic Sphere under Concentrated Loads. Jour. Appl. Mech., vol. 19, no. 4, Dec. 1952, pp. 413-421. (See also Discussion ry M. M. Frocht, Jour. Appl. Mech., vol. 20, no. 2, June 1953, pp. 304-305.)

TABLE II

CALCULATION OF NORMAL STRESS COMPONENTS FOR LINE C-C

\begin{tabular}{|c|c|c|c|c|c|c|c|c|c|}
\hline$\frac{z}{\mathrm{CO}^{\prime}}$ & $n_{t}$ & $n^{\prime \prime}$ & $\cos 2 \phi^{\prime \prime}$ & $n^{\prime \prime \prime}$ & $\cos 2 \phi^{\prime \prime \prime}$ & $n_{2}-n_{\text {(1) }}$ & $n_{z}-n_{y}$ & $\begin{array}{l}n_{x} \\
(3)\end{array}$ & $\begin{array}{l}n_{y} \\
\text { (1) }\end{array}$ \\
\hline 0 & 0.43 & 0.79 & 1.000 & 1.55 & 1.000 & 0. 79 & 1.55 & -0.36 & --1.12 \\
\hline 0.1 & 0.41 & 0.79 & 0.957 & 1.52 & 0.993 & 0.76 & 1.51 & -0.35 & -1.10 \\
\hline 0.2 & 0.36 & 0.78 & 0.841 & 1. 48 & 0.972 & 0.66 & 1.30 & -0.30 & -1.03 \\
\hline 0.3 & 0.30 & 0.77 & 0.674 & 1.30 & 0.942 & 0.52 & 1.22 & -0.22 & -0.92 \\
\hline 0.4 & 0.23 & 0.76 & 0.488 & 1.16 & 0.906 & 0.37 & 1.05 & -0.14 & -0.82 \\
\hline 0.5 & 0.17 & 0.74 & 0.302 & 1.00 & 0.863 & 0,22 & 0.86 & -0.05 & -0.69 \\
\hline 0.6 & 0.13 & 0.70 & 0.122 & 0.81 & 0.827 & 0.08 & 0.69 & 0.05 & -0.56 \\
\hline 0.7 & 0.10 & 0.66 & -0.035 & 0.70 & 0.809 & -0.02 & 0.57 & 0.12 & -0.47 \\
\hline 0.8 & 0.10 & 0.62 & -0.167 & 0. 56 & 0.819 & -0.10 & 0.46 & D. 20 & -0.36 \\
\hline 0.9 & 0.11 & 0.60 & -0.282 & 0.40 & 0.866 & -0.17 & 0.35 & 0.28 & -0.24 \\
\hline 1.0 & 0.18 & 0.59 & -0.375 & 0.18 & 1.000 & -0.22 & 0.18 & 0.40 & 0 \\
\hline
\end{tabular}

$1 n_{2}-n_{x}=n^{\prime \prime} \cos 2 \phi^{\prime \prime}$.

$n_{2}-n_{s}=n^{\prime \prime \prime}$ ens $2 \phi^{\prime \prime \prime}$

$n_{x}=n_{z}-\left(n_{x}-n_{x}\right)$

\section{TABI,E III}

CALCULATION OF SHEARING STRESS BY OBLIQUE INCIDENCE FOR IINE C-C

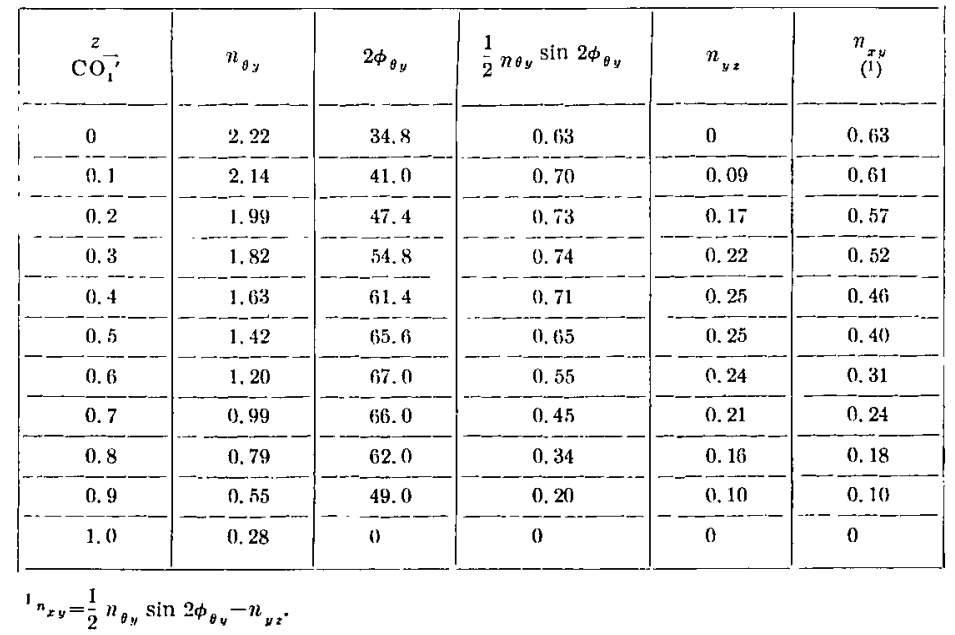

